Check for updates

Cite this: RSC Adv., 2019, 9, 25847

Received 7th June 2019

Accepted 6th August 2019

DOI: $10.1039 / c 9 r a 04296 b$

rsc.li/rsc-advances

\section{Insight into the adsorption mechanisms of methylene blue and chromium(III) from aqueous solution onto pomelo fruit peel}

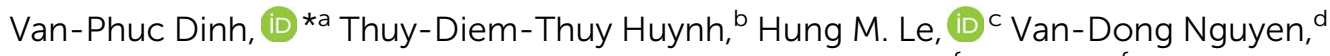 \\ Vinh-Ai Dao, ${ }^{a}$ N. Quang Hung, ${ }^{a}$ L. Anh Tuyen, ${ }^{e}$ Sunhwa Lee, ${ }^{f} J u n s i n ~ Y i,{ }^{f}$ \\ Trinh Duy Nguyen (D) ${ }^{g}$ and L. V. Tan ${ }^{b}$
}

In this study, the biosorption mechanisms of methylene blue (MB) and $\mathrm{Cr}(\mathrm{III})$ onto pomelo peel collected from our local fruits are investigated by combining experimental analysis with ab initio simulations. Factors that affect the adsorption such as $\mathrm{pH}$, adsorption time, adsorbent dosage and initial adsorbate concentration, are fully considered. Five isotherm models-Langmuir, Freundlich, Sips, Temkin, and Dubinin-Radushkevich-are employed to estimate the capacity of pomelo peel adsorption, whereas four kinetic models-pseudo-first-order, pseudo-second-order, Elovich and intra-diffusion models-are also used to investigate the mechanisms of the uptake of $\mathrm{MB}$ and $\mathrm{Cr}(\mathrm{III})$ onto the pomelo fruit peel. The maximum biosorption capacities calculated from the Langmuir models for $\mathrm{MB}$ and $\mathrm{Cr}(\mathrm{III})$ at $303 \mathrm{~K}$ are, $218.5 \mathrm{mg} \mathrm{g}^{-1}$ and $11.3 \mathrm{mg} \mathrm{g}^{-1}$, respectively. In particular, by combining, for the first time, the experimental FT-IR spectra with those obtained from ab initio calculations, we are able to demonstrate that the primary adsorption mechanisms of the uptake of MB onto pomelo fruit peel are electrostatic attraction and hydrogen-bond formations, whereas the adsorption mechanisms for $\mathrm{Cr}(\mathrm{III})$ are electrostatic attraction and $\mathrm{n}-\mathrm{d}$ interactions.

\section{Introduction}

Environmental pollution has become a challenging problem in the lives of humans and other creatures in developing nations and some other regions in the world. ${ }^{\mathbf{1}}$ Currently, government sectors in developing nations and other geographic regions are facing environmental problems, especially the release of organic compounds and heavy metal pollution from plating and textile dyeing industries, that lead to human health problems. Among the chemicals exhausted from these factories, methylene blue (MB) is responsible

${ }^{a}$ Institute of Fundamental and Applied Sciences, Duy Tan University, 10C Tran Nhat Duat Street, District 1, Ho Chi Minh City 700000, Vietnam. E-mail: dinhvanphuc@ duytan.edu.vn

${ }^{b}$ Industrial University of Ho Chi Minh City, 12 Nguyen Van Bao, Ward 4, Go Vap Disc., HCM City, Vietnam

${ }^{c}$ Center for Innovative Materials and Architectures (INOMAR), Vietnam National University (VNUHCM), Ho Chi Minh City, 721337, Vietnam

${ }^{d}$ VNUHCM-University of Science, 227 Nguyen Van Cu Street, District 5, Ho Chi Minh City, Vietnam

${ }^{e}$ Center for Nuclear Techniques, Vietnam Atomic Energy Institute, Ho Chi Minh City, 700000, Vietnam

${ }^{f}$ School of Information and Communication Engineering, Sungkyunkwan University, Suwon 16419, Korea

${ }^{8}$ Center of Excellence for Green Energy and Environmental Nanomaterials (CE@GrEEN), Nguyen Tat Thanh University, 300A Nguyen Tat Thanh, District 4, Ho Chi Minh City, Vietnam for fast heart rate, vomiting (spitting), shock, Heinz body formation, cyanosis, jaundice (icterus), quadriplegia and tissue necrosis in humans, ${ }^{2-5}$ whereas chromium compounds cause nausea, diarrhoea, liver failure, dermatitis (eczema), internal haemorrhage (bleeding) and respiratory troubles. ${ }^{6-9}$ Various chemical and physical methods have been employed to remove the MB and chromium compounds from aqueous solution, such as solvent extraction, ${ }^{\mathbf{8}}$ adsorption, ${ }^{10-13}$ coagulation, ${ }^{14-16}$ membrane separation, ${ }^{17,18}$ ion exchange, ${ }^{19,20}$ electrodeposition, ${ }^{21}$ and reverse osmosis. ${ }^{22}$ It is wellknown that, adsorption is a promising method to remove these compounds from waste water since this method has high enrichment efficiency and can be easily used to separate the phases. ${ }^{23-26}$

In recent years, the use of agricultural waste as a biosorbent to remove $\mathrm{MB}$ and $\mathrm{Cr}$ (III) has been widely applied. The reason is that biosorbent has many significant advantages such as simple implementation, very low cost, no or minimal use of chemicals and high efficiency, as compared to other materials. Several biosorbents have been used to treat $\mathrm{MB}$ and $\mathrm{Cr}(\mathrm{III})$ in waste solution such as oak banana peels, ${ }^{11}$ sawdust, ${ }^{27}$ lawn grass, ${ }^{28}$ de-oiled algae, ${ }^{29}$ mango leaves, ${ }^{30}$ corn cobs, sunflower ${ }^{31}$ and grapefruit. ${ }^{32}$

Pomelo, or Citrus maxima, has been popularly planted in Dong Nai Province, Vietnam. Among the tropical fruits, pomelo is known as one of special fruits with a thick peel and a large amount of pomelo peel waste is generated every year. Although pomelo has been widely used in food industry and pharmacy, its usages as well as products made from its peel as a biosorbent to remove toxic 
organic compounds and heavy metals from waste water have still been insignificant..$^{33-36}$ However, the adequate insights into the adsorption mechanisms using the pomelo peel have been lacked so far. $^{37-39}$ In addition, despite of the fact that the Fourier-transform infrared spectroscopy (FTIR) plays a crucial role in studying the adsorption characteristics of pomelo fruit peel, ${ }^{38,39}$ this method was unable to provide an accurate analysis for the interaction of adsorbates with lignin, cellulose, and pectin in pomelo fruit peel. Recently, the computer simulation using the ab initio modelling has been extensively applied to simulate the IR spectra of adsorbents, based on which one can exactly understand the relationships between the internal interactions and the shifts inside the experimental FT-IR spectra. ${ }^{\mathbf{4 0 , 4 1}}$ It is therefore our hope that by combing the FT-IR measurement with the ab initio simulation, we will be, for the first time, able to deeply understand the adsorption mechanisms of removing $\mathrm{MB}$ and $\mathrm{Cr}$ (III) from wastewater solution using pomelo fruit peel. This is the goal of the present study.

\section{Materials and methods}

\subsection{Chemicals}

$\mathrm{MB}\left(\mathrm{C}_{16} \mathrm{H}_{18} \mathrm{ClN}_{3} \mathrm{~S}\right)$, which was used as an adsorbate in the present study, was prepared by dissolving the methylene blue (solid phase) in double-distilled water. The chemical structure and UV-Vis absorption spectrum of $\mathrm{MB}$ in the solution are shown in Fig. 1. Four characteristic peaks (246, 292, 613 and $664 \mathrm{~nm}$ ) of MB are observed and they are similar to those reported previously. ${ }^{\mathbf{4 2}}$

Another adsorbate, $\mathrm{Cr}(\mathrm{III})\left(\mathrm{Cr}\left(\mathrm{NO}_{3}\right)_{3}\right)$ ions, was prepared by dissolving $\mathrm{Cr}(\mathrm{III})\left(1000 \mathrm{mg} \mathrm{L}^{-1}\right)$ in double-distilled water.

All the chemicals, which are purchased from Merck, are in the analytical grade.

\subsection{Preparation of biosorbent}

Pomelo fruit peel, which was collected from Dong Nai province, Vietnam, was cleaned in double-distilled water and then dried at $80^{\circ} \mathrm{C}$ in 24 hours. In the next step, the product was crushed to pieces of approximately $0.5-1 \mathrm{~mm}$ each and washed 2-3 times with double-distilled water prior to be dried in the oven.

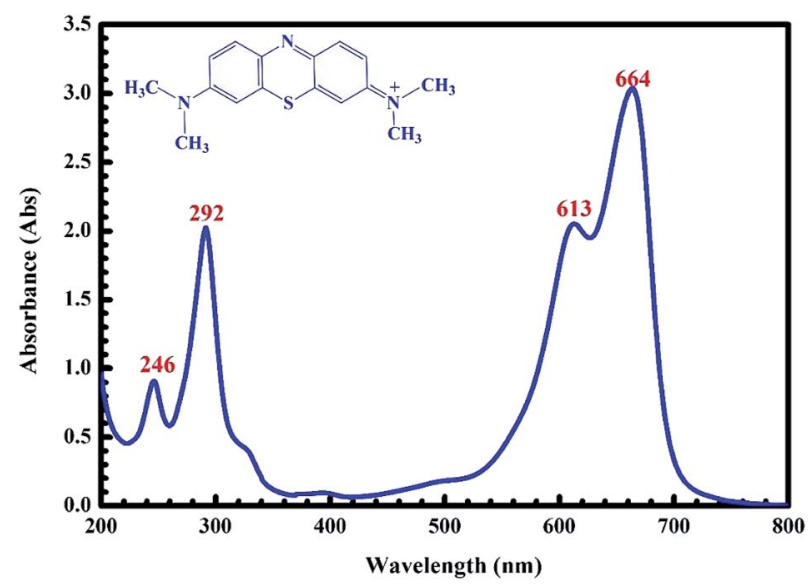

Fig. 1 UV-Vis absorption spectra of the MB solution.

\subsection{Characterisation of biosorbent}

The Ultra-high resolution scanning electron microscopy S4800 (Hitachi) and Energy-dispersive X-ray Spectroscopy (JSM-6490LA) have been used to investigate the surface properties and elemental composition of pomelo fruit peels, whereas the Spectrum GX-FTIR (PerkinElmer, USA) has been applied to record their IR spectra before and after the adsorption over the wave-number range from 4000 to $400 \mathrm{~cm}^{-1}$.

The $\mathrm{pH}$ at the potential of zero-point charge $\left(\mathrm{pH}_{\mathrm{PZC}}\right)$, which describes the condition when the electrical charge density on a surface becomes zero, is an important instrument. In the present work, the $\mathrm{pH}_{\mathrm{PzC}}$ of the materials was determined by using the salt addition method..$^{43}$ Here, $0.2 \mathrm{~g}$ of each pomelo fruit peel is placed in ten $100 \mathrm{~mL}$ plastic beakers including $50.0 \mathrm{~mL}$ of $0.1 \mathrm{M} \mathrm{KNO}_{3}$. The $\mathrm{pH}$ values are adjusted using a pH-meter (MARTINI Instruments Mi-150, Romania) from 2 to $11( \pm 0.1)$ with $0.1 \mathrm{M} \mathrm{HNO}_{3}$ or $0.1 \mathrm{M}$ $\mathrm{NaOH}$ as required in each beaker. The prepared solutions are then shaken for $24 \mathrm{~h}$ until the equilibrium is reached. After that, each solution containing the typical $\mathrm{pH}$ is measured. By plotting the initial $\mathrm{pH}\left(\mathrm{pH}_{\mathrm{o}}\right)$ versus the difference between the initial and final $\mathrm{pH}$ values $(\Delta \mathrm{pH})$, the $\mathrm{pH}_{\mathrm{PZC}}$ is chosen at the point where $\mathrm{pH}=0$.

The UV-Vis spectrum of MB was determined by using a spectrophotometer (Jasco-V630) with a measurement range from 800 to $200 \mathrm{~nm}$ and a data interval of $0.1 \mathrm{~nm}$.

\subsection{Batch adsorption experiments}

In this work, the batch technique was utilised to investigate the uptake of $\mathrm{MB}$ and $\mathrm{Cr}(\mathrm{III})$ from aqueous solution onto pomelo fruit peel. Initially, we placed $0.2 \mathrm{~g}$ of the material into a $100 \mathrm{~mL}$ conical flask with $50 \mathrm{~mL} \mathrm{MB}$ or $\mathrm{Cr}(\mathrm{III})$. The influence of $\mathrm{pH}$ on the solution (within a range of 2-11 for MB and 2-6 for $\operatorname{Cr}(\mathrm{III})$ ), adsorption time (from $5 \mathrm{~min}$ to $240 \mathrm{~min}$ ), and ionic strength was examined by varying the $\mathrm{KCl}$ concentration from 0 to $0.5 \mathrm{M}$, and initial concentrations of $\mathrm{MB}$ (from 5 to $1000 \mathrm{mg} \mathrm{L}^{-1}$ ) and $\mathrm{Cr}$ (III) (from 5 to $50 \mathrm{mg} \mathrm{\textrm {L } ^ { - 1 }}$ ). Each experiment was conducted with three replications. Next, the concentrations of $\mathrm{MB}$ and $\mathrm{Cr}(\mathrm{III})$ in the filtrate before and after the adsorption were measured using the UV-Vis and atomic absorption (AAS) spectrophotometers, respectively. For every 10 samples, the calibration, verification and standardisation were continuously applied during the measurement.

To calculate the percentage of removal (\% removal) and adsorption capacity $\left(q_{\mathrm{e}}\right)$, we have used the following massbalance equations

$$
\% \text { removal }=\frac{\left(C_{\mathrm{o}}-C_{\mathrm{e}}\right) 100 \%}{C_{\mathrm{o}}},
$$

and

$$
q_{\mathrm{e}}=\frac{\left(C_{\mathrm{o}}-C_{\mathrm{e}}\right) V}{m},
$$

where $C_{\mathrm{o}}\left(\mathrm{mg} \mathrm{L}^{-1}\right)$ is the initial concentration, whereas $C_{\mathrm{e}}(\mathrm{mg}$ $\mathrm{L}^{-1}$ ) is the concentration at the equilibrium. 


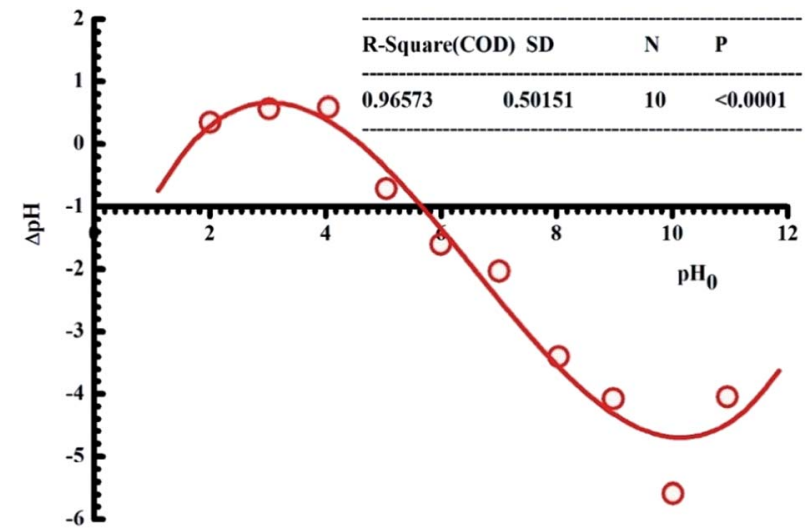

Fig. 2 Plot of the point of zero charge of pomelo fruit peel.

\subsection{Adsorption isotherm}

In order to describe the interactions between the adsorbate molecules and biosorbent surface as well as their distribution between the liquid and solid phases in an equilibrium state, many different well-known models with two or three fitting

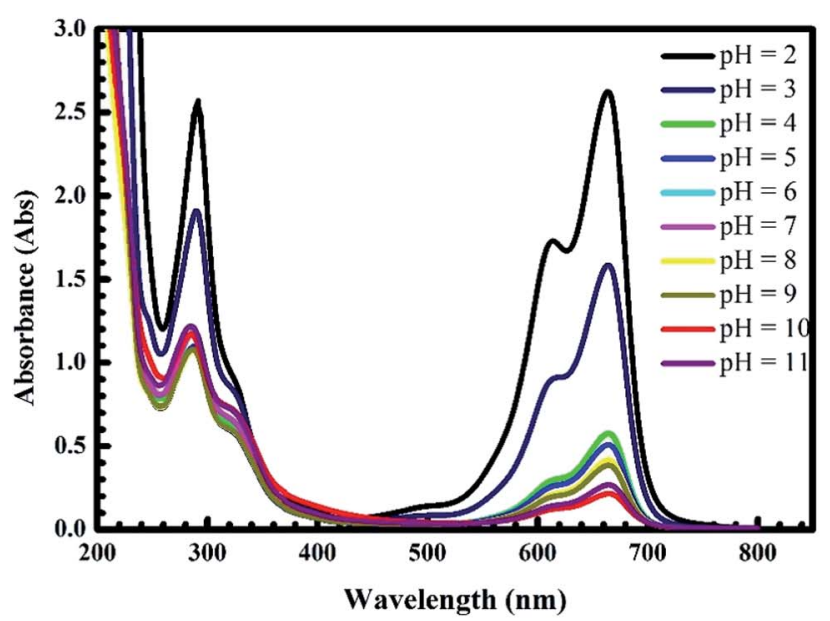

(a)

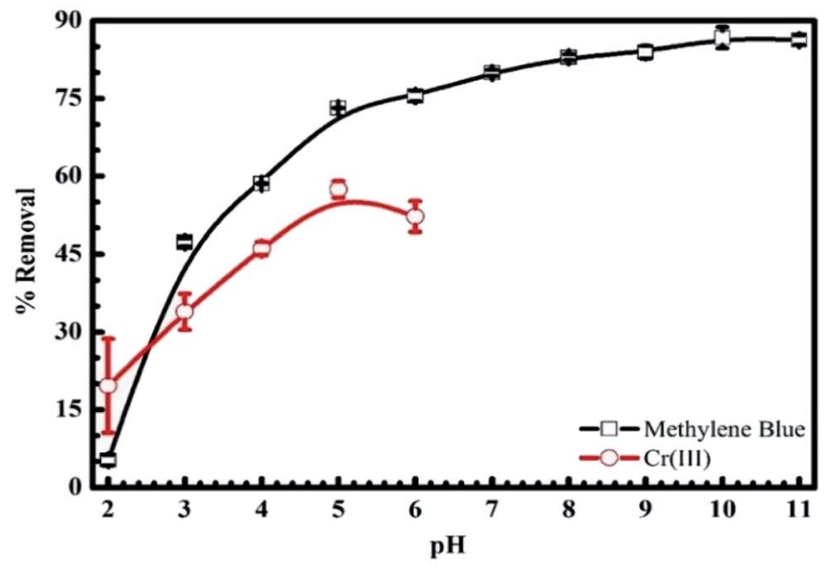

(b)

Fig. 3 UV-Vis spectra of MB after the uptake at different $\mathrm{pH}$ values (a) and effects of $\mathrm{pH}$ on the adsorption of $\mathrm{MB}$ and $\mathrm{Cr}(\mathrm{III})$ onto pomelo fruit peel (b). parameters can be used. In the present study, five models including Langmuir, Freundlich, Sips, Temkin and DubininRadushkevich were chosen.

2.5.1. Two-parameter models. The Langmuir model is used to describe the adsorption of $\mathrm{MB}$ and $\mathrm{Cr}(\mathrm{III})$ by assuming that the monolayer adsorption occurs on a homogenous surface without any interaction between the adsorbed ions. ${ }^{44}$ Two key parameters, $Q_{\mathrm{m}}$, related to the monolayer adsorption capacity and $K_{\mathrm{L}}$, being the Langmuir constant, were determined based on a nonlinear form of Langmuir isotherm equation as $^{45}$

$$
q_{\mathrm{e}}=\frac{Q_{\mathrm{m}} K_{\mathrm{L}} C_{\mathrm{e}}}{1+K_{\mathrm{L}} C_{\mathrm{e}}},
$$

where $q_{\mathrm{e}}\left(\mathrm{mg} \mathrm{g}^{-1}\right)$ is the amount of adsorbed $\mathrm{MB}$ or $\mathrm{Cr}(\mathrm{III})$ per unit of mass of the adsorbent, whereas $C_{\mathrm{e}}\left(\mathrm{mg} \mathrm{L}^{-1}\right)$ is the concentration of $\mathrm{MB}$ or $\mathrm{Cr}(\mathrm{III})$ remaining in the solution.

The Freundlich model is utilised to estimate the adsorption of $\mathrm{MB}$ and $\mathrm{Cr}$ (III) by considering the multilayer adsorption, which occurs on a heterogeneous surface and contains a adsorbate-adsorbent interaction. ${ }^{44}$ Two main parameters, $K_{\mathrm{F}}$ $\left(\mathrm{L} \mathrm{g}^{-1}\right)$ and $n$, corresponding, respectively, to the Freundlich constant and heterogeneity of the adsorption surface, were estimated by using a nonlinear form of the Freundlich isotherm equation given $\mathrm{as}^{\mathbf{4 6}}$

$$
q_{\mathrm{e}}=K_{\mathrm{F}} C_{\mathrm{e}}^{1 / n}
$$

Unlike the Langmuir and Freundlich models, the Temkin model proposes that the adsorption heat of all the molecules in the layers should linearly decrease with the coverage due to the adsorbent-adsorbate interactions. In addition, within the Tempkin model, the adsorption is characterised by a uniform distribution of the bonding energy up to some maximum values of the binding energy. ${ }^{44}$ The Temkin isotherm equation is often expressed in terms of the following nonlinear form ${ }^{47}$

$$
q_{\mathrm{e}}=\frac{R T}{b_{\mathrm{T}}} \ln \left(K_{\mathrm{T}} C_{\mathrm{e}}\right)
$$

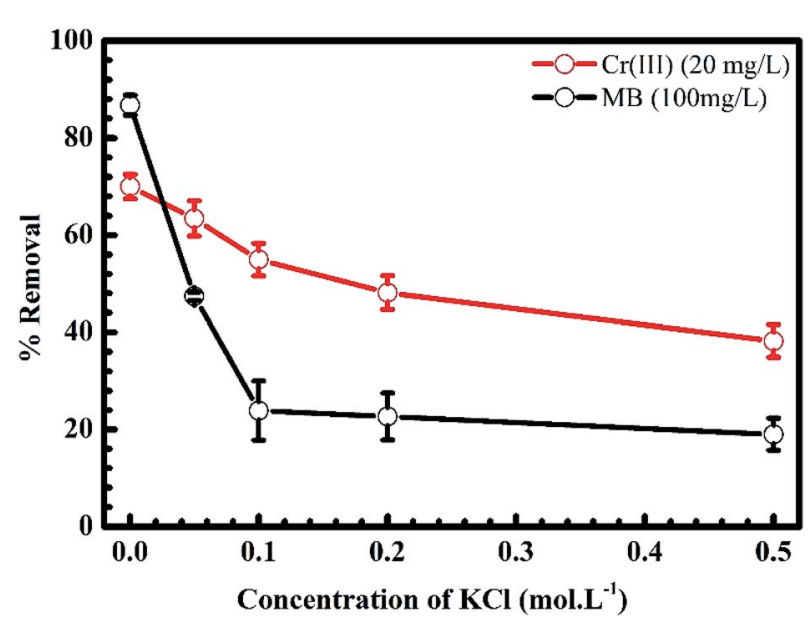

Fig. 4 Effects of $\mathrm{KCl}$ concentration or ionic strength on the adsorption of $\mathrm{MB}$ and $\mathrm{Cr}(\mathrm{II})$ onto pomelo fruit peel (shaking speed $=240 \mathrm{rpm}$, adsorption time $=150 \mathrm{~min}$, error bar $=\mathrm{SD}, n=3$ ). 


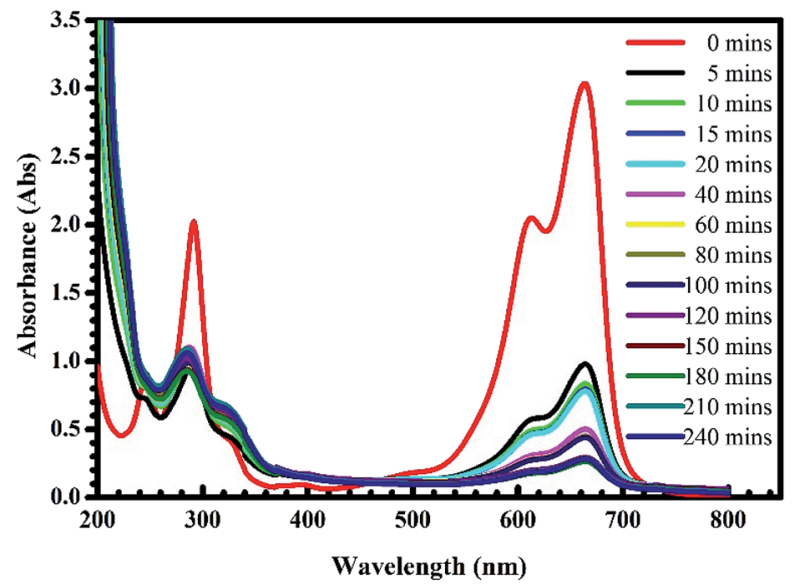

(a)

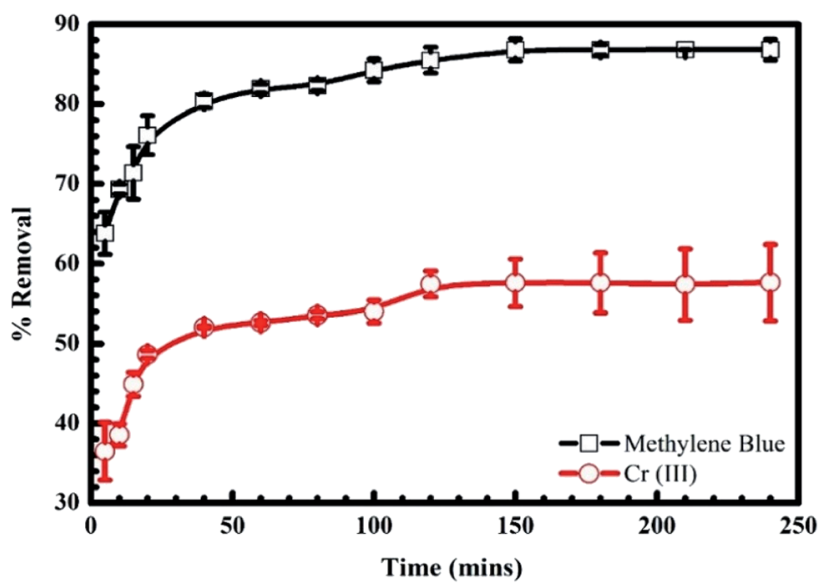

(b)

Fig. 5 UV-Vis spectra of MB before and after the adsorption at different times (a) and effects of time on the adsorption of $M B$ and $\mathrm{Cr}$ (III) onto pomelo fruit peel (b) (shaking speed $=240 \mathrm{rpm}, \mathrm{pH}=10$ of $\mathrm{MB}$ and $\mathrm{pH}=5$ of $\mathrm{Cr}(\mathrm{II})$, error bar $=\mathrm{SD}, n=3)$.

where $K_{\mathrm{T}}\left(\mathrm{L} \mathrm{mol}^{-1}\right)$ is the binding constant at the equilibrium, which relates to the maximum binding energy, whereas $b_{\mathrm{T}}(\mathrm{kJ}$ $\left.\mathrm{mol}^{-1}\right)$ is associated with the adsorption heat. $R\left(8.314 \times 10^{-3}\right.$ $\mathrm{kJ} \mathrm{K}^{-1} \mathrm{~mol}^{-1}$ ) and $T(\mathrm{~K})$ in eqn (5) are the universal gas constant and temperature, respectively.

In addition, to determine the physical/chemical nature of the adsorption, the Dubinin-Radushkevich model was also used. The isotherm equation of the Dubinin-Radushkevich model is given as $^{44}$

$$
q_{\mathrm{e}}=q_{\mathrm{m}} \mathrm{e}^{\left(-\beta \varepsilon^{2}\right)},
$$

where $\beta\left(\mathrm{mol}^{2} \mathrm{~J}^{-2}\right)$ and $\varepsilon=R T \ln \left(1+1 / C_{\mathrm{e}}\right)\left(\mathrm{J} \mathrm{mol}^{-1}\right)$ are the Dubinin-Radushkevich isotherm constant and Polanyi potential $\left(\mathrm{J} \mathrm{mol}^{-1}\right)$, respectively. The mean adsorption energy $E(\mathrm{~kJ}$ $\mathrm{mol}^{-1}$ ), a parameter which is used to determine whether the adsorption is physical or chemical, can be then calculated from the following equation

$$
E=\frac{1}{\sqrt{-2 \beta}} .
$$

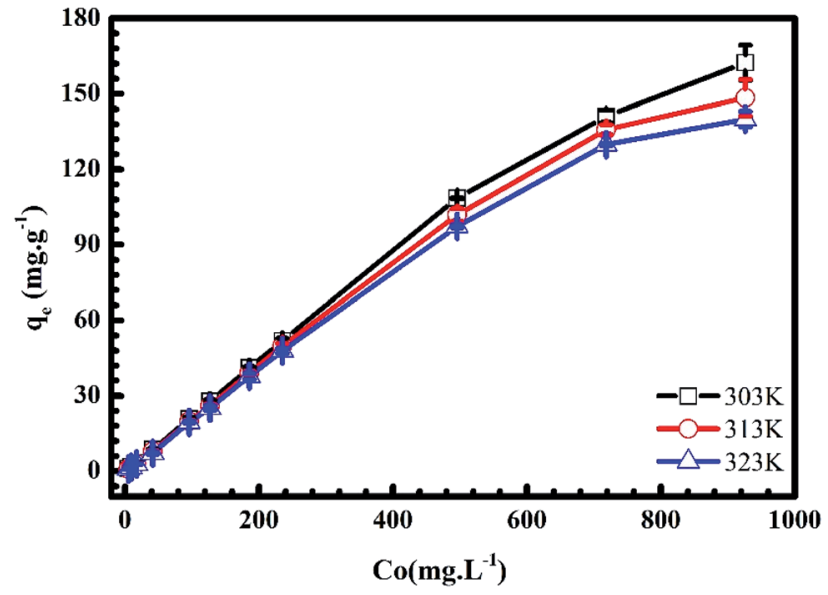

Fig. 6 Effects of initial concentration on the adsorption of MB onto pomelo fruit peels.

For instance, if $E$ is smaller than $8 \mathrm{~kJ} \mathrm{~mol}^{-1}$, the adsorption is physical. If $E$ is in the range of $8-16 \mathrm{~kJ} \mathrm{~mol}^{-1}$, the adsorption is ion-exchange, whereas the adsorption is chemical if $E$ is higher than $16 \mathrm{~kJ} \mathrm{~mol}^{-1} .^{48}$

2.5.2 Three-parameter models. In addition to the twoparameter models, different three-parameter models have also been widely considered for the description of adsorption isotherms. Among them, the Sips model, which is a combination of the Langmuir and Freundlich models, was selected. This model was proposed to describe the heterogeneous adsorption systems and to overcome the limitation on the increase of adsorbate concentration within the Freundlich model. This model has the form as ${ }^{\mathbf{4 4}}$

$$
q_{\mathrm{e}}=\frac{Q_{\mathrm{S}} C_{\mathrm{e}}^{\beta_{\mathrm{S}}}}{1+\alpha_{\mathrm{s}} C_{\mathrm{e}}^{\beta_{\mathrm{S}}}},
$$

where $\alpha_{\mathrm{S}}\left(\mathrm{L} \mathrm{mg}^{-1}\right)$ and $\beta_{\mathrm{S}}$ are, respectively, the Sips isotherm constant and exponent, whereas $Q_{\mathrm{S}}$ is the Sips constant. The Sips model reduces to the Freundlich isotherm when the adsorbate concentration is low, whereas it becomes the Langmuir isotherm in the region of high concentration.

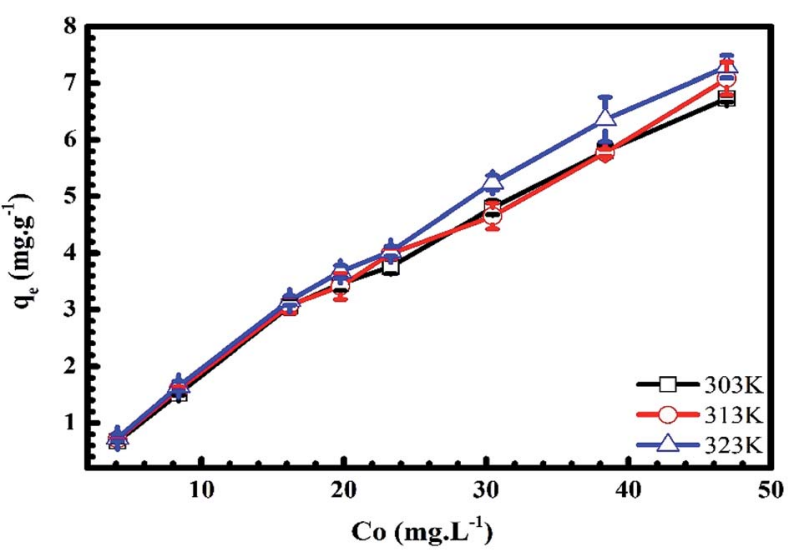

Fig. 7 Effects of initial concentration on the adsorption of $\mathrm{Cr}$ (III) onto pomelo fruit peels. 


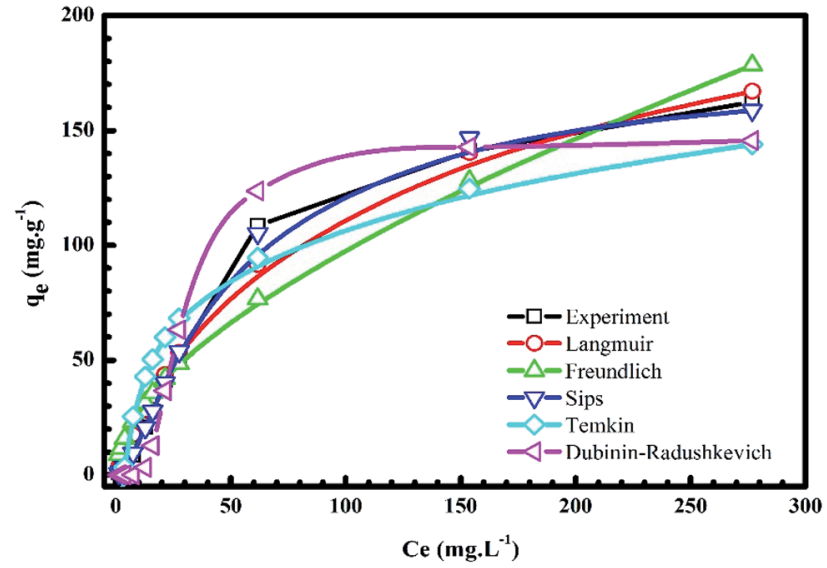

(a)

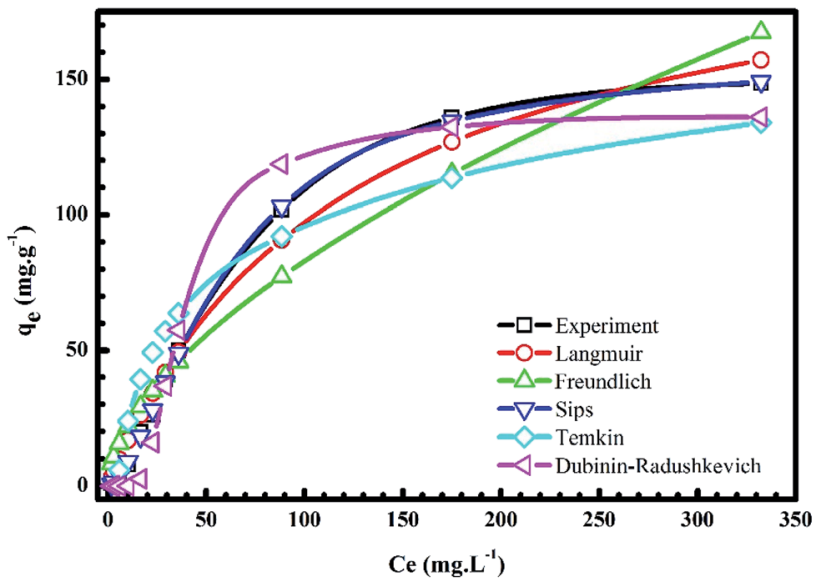

(b)

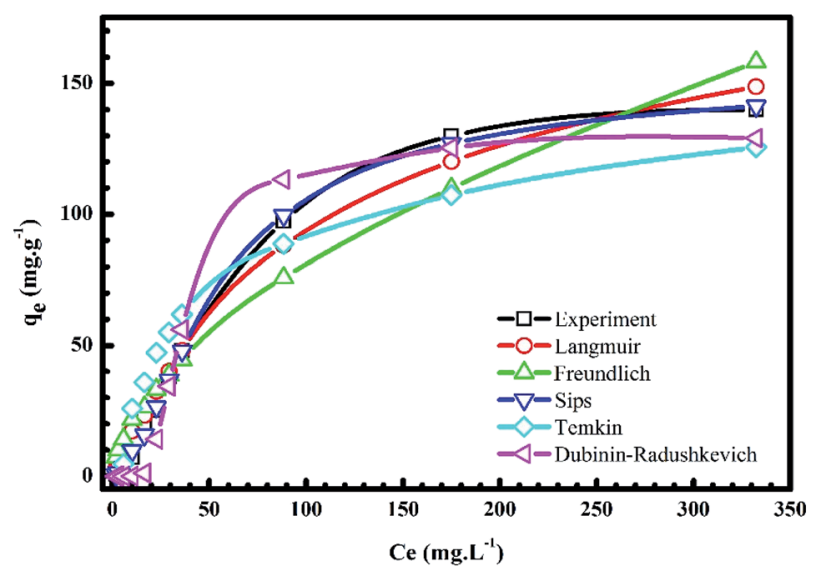

(c)

Fig. 8 Plots of nonlinear isotherm models of the adsorption of $M B$ onto pomelo fruit peels at $303 \mathrm{~K}(\mathrm{a}), 313 \mathrm{~K}$ (b) and $323 \mathrm{~K}(\mathrm{c})$.

\subsection{Data analysis}

In order to identify the best fitted model for the adsorption process, the values of the chi-square $\left(\chi^{2}\right)$, root mean square error (RMSE) and coefficient of determination $\left(R^{2}\right)$ of the nonlinear optimisation methods are calculated by using the following equations

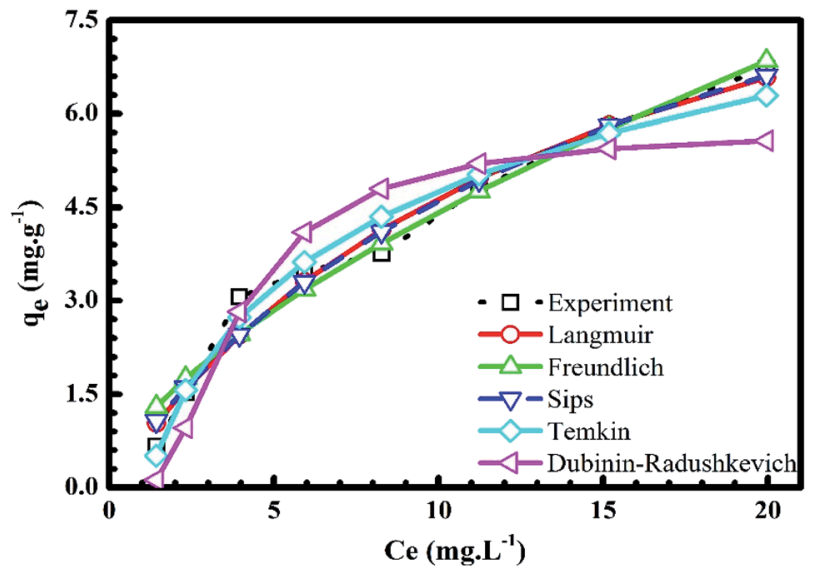

(a)

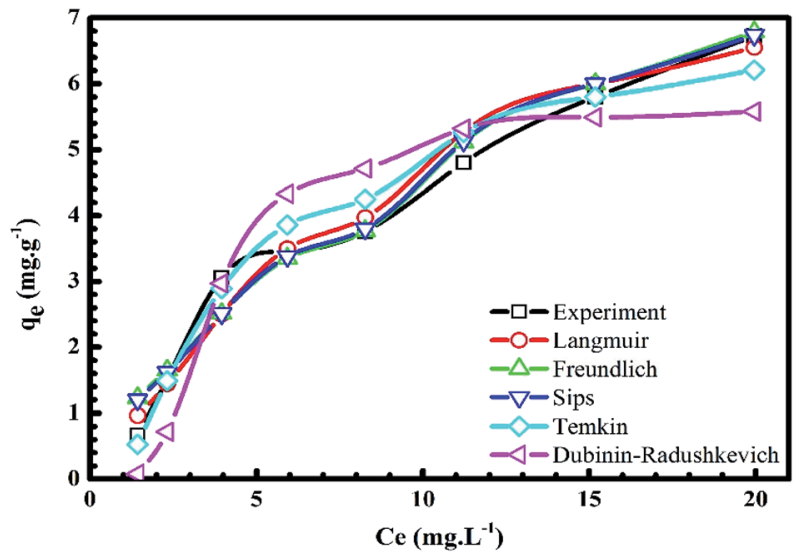

(b)

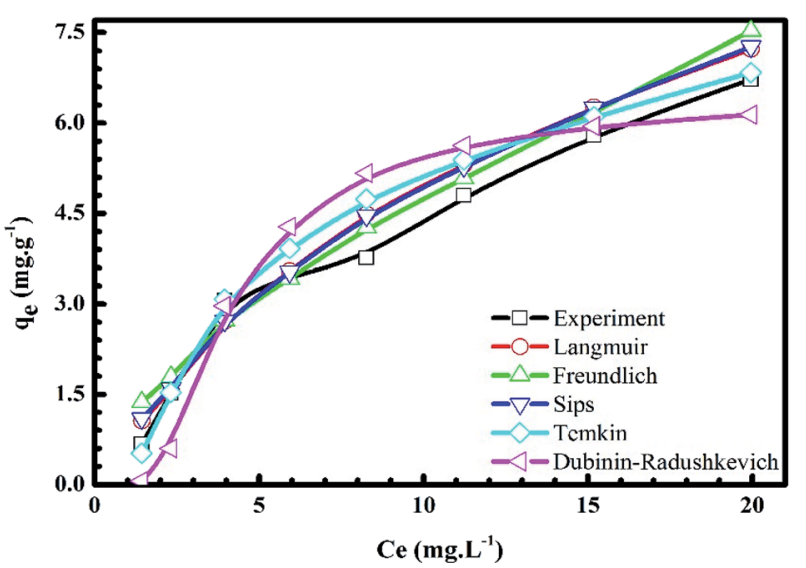

(c)

Fig. 9 Plots of nonlinear isotherm models of the adsorption of $\mathrm{Cr}(\mathrm{III})$ onto pomelo fruit peels at $303 \mathrm{~K}$ (a), $313 \mathrm{~K}$ (b) and $323 \mathrm{~K}$ (c).

$$
\begin{aligned}
R^{2} & =1-\frac{\sum_{n=1}^{n}\left(q_{\mathrm{e}, \text { meas }}-q_{\mathrm{e}, \mathrm{calc}}\right)^{2}}{\sum_{n=1}^{n}\left(q_{\mathrm{e}, \text { meas }}-\overline{q_{\mathrm{e}, \mathrm{calc}}}\right)^{2}}, \\
\mathrm{RMSE} & =\sqrt{\frac{1}{n-1} \sum_{n=1}^{n}\left(q_{\mathrm{e}, \text { meas }}-q_{\mathrm{e}, \mathrm{calc}}\right)^{2}},
\end{aligned}
$$


Table 1 Nonlinear isotherm parameters

\begin{tabular}{|c|c|c|c|c|c|c|c|}
\hline \multirow{2}{*}{ Isotherm models } & \multicolumn{7}{|l|}{ Parameters } \\
\hline & Temperature & \multicolumn{3}{|l|}{ MB } & \multicolumn{3}{|l|}{$\mathrm{Cr}(\mathrm{III})$} \\
\hline \multirow[t]{3}{*}{ Langmuir } & $K_{\mathrm{L}}$ & 0.01168 & 0.00833 & 0.00693 & 0.0700 & 0.0725 & 0.0792 \\
\hline & $q_{\mathrm{m}}\left(\mathrm{mg} \mathrm{g}^{-1}\right)$ & 218.5 & 213.9 & 207.4 & 11.3 & 11.4 & 12.4 \\
\hline & $\chi^{2}$ & 39.71 & 47.78 & 45.72 & 0.3754 & 0.3493 & 0.2759 \\
\hline \multirow[t]{5}{*}{ Freundlich } & $n$ & 1.78 & 1.71 & 1.68 & 1.58 & 1.58 & 1.59 \\
\hline & $K_{\mathrm{F}}$ & 7.51 & 5.65 & 4.69 & 1.03 & 1.06 & 1.23 \\
\hline & RMSE & 14.76 & 14.41 & 13.33 & 0.3655 & 0.3789 & 0.3482 \\
\hline & $R^{2}$ & 0.9366 & 0.9309 & 0.9345 & 0.9680 & 0.9670 & 0.9757 \\
\hline & $\chi^{2}$ & 203.9 & 209.8 & 187.3 & 0.7751 & 0.5716 & 0.6704 \\
\hline & $R^{2}$ & 0.9982 & 0.9995 & 0.9986 & 0.9751 & 0.9672 & 0.9839 \\
\hline & $\chi^{2}$ & 0.8380 & 0.8374 & 2.083 & 0.4154 & 0.5210 & 0.3077 \\
\hline \multirow[t]{5}{*}{ Temkin } & $K_{\mathrm{T}}\left(\mathrm{L} \mathrm{mg}^{-1}\right)$ & 0.2901 & 0.2077 & 0.1820 & 1.149 & 1.23 & 1.15 \\
\hline & $b_{\mathrm{T}}\left(\mathrm{kJ} \mathrm{mol}^{-1}\right)$ & 0.07675 & 0.08225 & 0.08981 & 0.8818 & 1.019 & 1.0603 \\
\hline & RMSE & 20.00 & 19.20 & 18.74 & 0.3342 & 0.4619 & 0.3608 \\
\hline & $R^{2}$ & 0.8835 & 0.8774 & 0.8704 & 0.9732 & 0.9509 & 0.9739 \\
\hline & $\chi^{2}$ & 1206 & 1271 & 1283 & 0.2185 & 0.3298 & 0.2530 \\
\hline \multirow[t]{6}{*}{ Dubinin-Radushkevich } & $\hat{Q}_{\mathrm{D}-\mathrm{R}}\left(\mathrm{mol} \mathrm{g}^{-1}\right)$ & 146.9 & 137.5 & 130.6 & 5.757 & 5.78 & 6.37 \\
\hline & $\beta$ & 104.9 & 172.2 & 226.9 & 2.201 & 1.856 & 1.704 \\
\hline & $E\left(\mathrm{~kJ} \mathrm{~mol}^{-1}\right)$ & 0.06905 & 0.05389 & 0.04694 & 0.4766 & 0.5190 & 0.5418 \\
\hline & RMSE & 11.28 & 9.899 & 9.927 & 0.7383 & 0.8732 & 0.8362 \\
\hline & $R^{2}$ & 0.9630 & 0.9674 & 0.9636 & 0.8694 & 0.8246 & 0.8600 \\
\hline & $\chi^{2}$ & 44.28 & 37.28 & 39.39 & 1.347 & 1.856 & 1.950 \\
\hline
\end{tabular}

and

$$
\chi^{2}=\sum_{n=1}^{n} \frac{\left(q_{\mathrm{e}, \text { meas }}-q_{\mathrm{e}, \text { calc }}\right)^{2}}{q_{\mathrm{e}, \text { calc }}} .
$$

The smallest values of RMSE and $\chi^{2}$ indicate which model is best fitted to the experimental data.

\section{Results and discussion}

\subsection{Factors affecting the adsorption of $\mathrm{MB}$ and $\mathrm{Cr}$ (III)}

3.1.1. $\mathbf{p H} . \mathrm{pH}$ is one of the essential factors affecting the adsorption of adsorbates onto the surface of materials based on the electrostatic interaction. When $\mathrm{pH}$ of a solution is smaller than its $\mathrm{pH}_{\mathrm{PZC}}$ value $\left(\mathrm{pH}<\mathrm{pH}_{\mathrm{PZC}}\right)$, the adsorption sites will be positively charged, which is thus available for the uptake of anions. By

Table 2 Comparison the monolayer maximum adsorption capacity with other materials

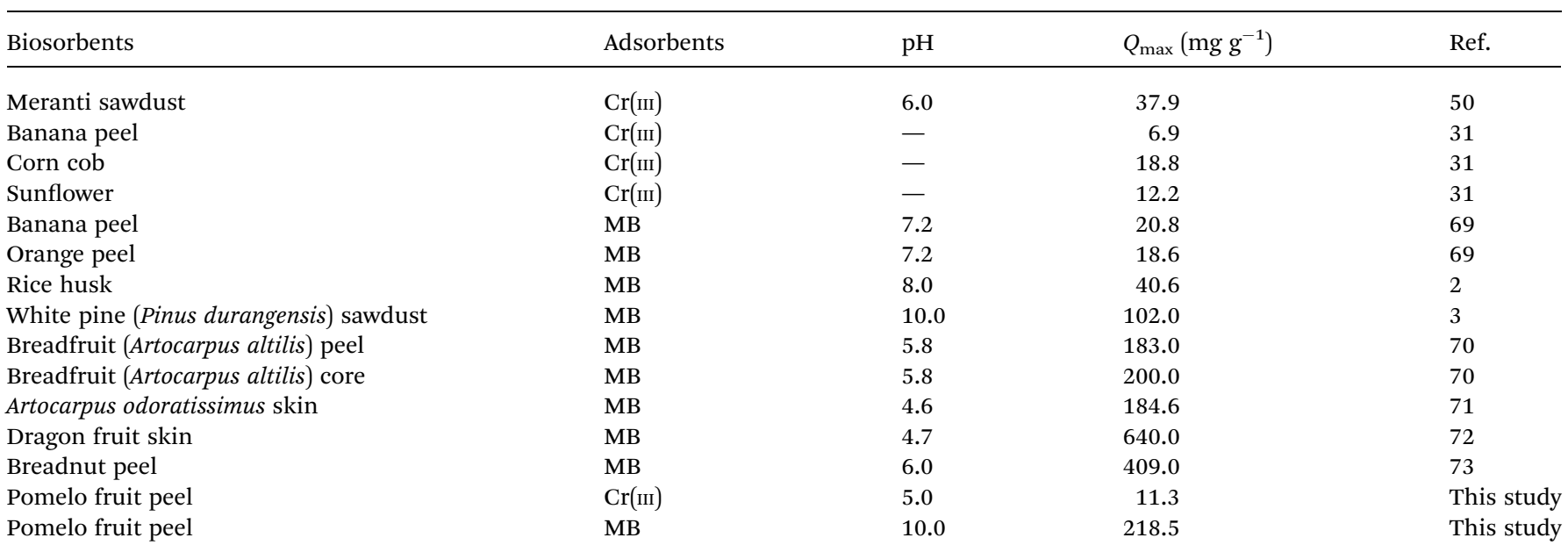


contrast, the adsorption sites will be negatively charged if $\mathrm{pH}$ is higher than its $\mathrm{pH}_{\mathrm{PZC}}$ value and consequently the adsorption of cations is favourable. In this work, the $\mathrm{pH}_{\mathrm{PZC}}$ value of pomelo fruit peels is determined to be approximately 4.5 (Fig. 2).

Fig. 3a shows that the absorbance intensity of MB after the adsorption versus the wavelength decreases dramatically with the $\mathrm{pH}$ values from 2 to 3 . It slightly falls when $\mathrm{pH}$ increases 4 to 9 and reaches maximum at $\mathrm{pH}=10$ (see the black line in Fig. 3b). At the same time, the uptake of $\mathrm{Cr}(\mathrm{III})$ onto pomelo fruit peel rises dramatically with the $\mathrm{pH}$ values from 2 to 4 and then attains the maximum value at $\mathrm{pH}=5.0$, before falling minimally at the end of the experiment (see the red line in Fig. 3b). These results show that the changes in the $\mathrm{pH}$ values significantly affect the adsorption of $\mathrm{MB}$ and $\mathrm{Cr}(\mathrm{III})$ because of the transition of the surface charge from the positive to negative regions that facilitates the adsorption of cation.

3.1.2. Ion strength. Fig. 4 shows the influence of the ionic strength on the uptake of MB and $\mathrm{Cr}$ (III) onto pomelo fruit peel. In this figure, the percentage of $\mathrm{MB}$ being removed from the solution significantly drops from roughly $90 \%$ to about $20 \%$ with the slight increase of $\mathrm{KCl}$ concentration or ionic strength from 0.0 to $0.1 \mathrm{~mol} \mathrm{~L}^{-1}$. Increasing the ionic strength further does no change much the percentage of removal of MB. For the

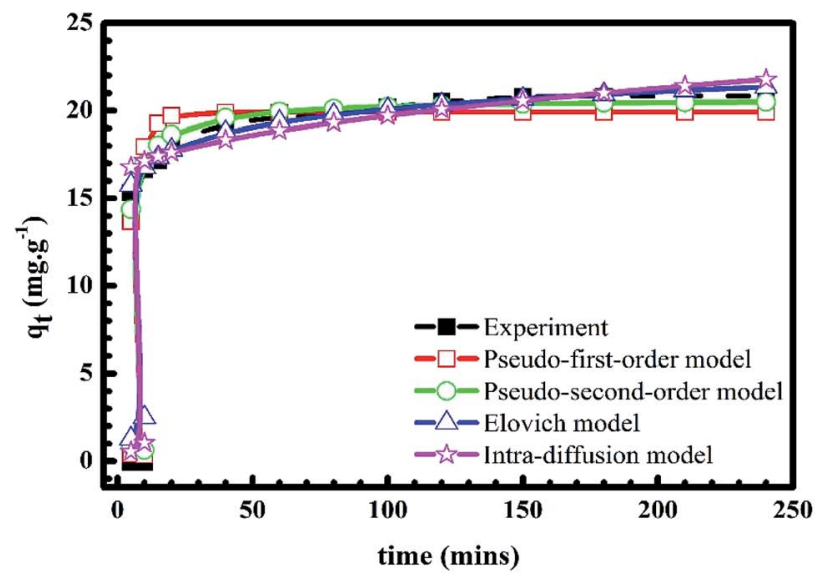

(a)

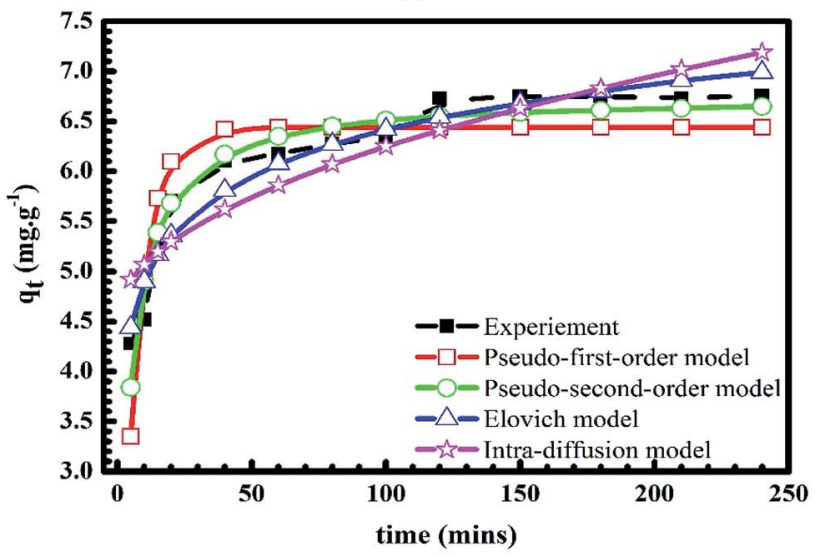

(b)

Fig. 10 Plots of kinetic models of the adsorption of MB (a) and $\mathrm{Cr}(\mathrm{III})(\mathrm{b})$ onto pomelo fruit peel. removal percentage of $\mathrm{Cr}(\mathrm{III})$, one can clearly see a slight fall from approximately $70 \%$ to about $40 \%$ with increasing the ionic strength. Obviously, the presence of electrolytes leads to the above reduction of the adsorption of $\mathrm{MB}$ and $\mathrm{Cr}$ (III) onto pomelo fruit peel. One explanation is that there is a screening effect (known as the electrostatic screening) existed between the positively charged surface of pomelo fruit peel and MB molecules or $\mathrm{Cr}$ (III) ions. This finding is consistent with the those reported by Salazar-Rabago et al. and Tran et al.,49 Moreover, these data might suggest that the electrostatic force plays an instrumental role in the adsorption mechanism considered in the present study.

3.1.3. Adsorption time. Fig. 5a depicts the spectra of $\mathrm{MB}$ after the adsorption at different times. It can be seen that there is a downward trend in the intensity of absorbance after the adsorption without any shifts of the wavelength, indicating clearly that the adsorption is unique. The influence of time on the uptake of $\mathrm{MB}$ and $\mathrm{Cr}(\mathrm{III})$ onto pomelo fruit peel is presented in Fig. 5b, in which the adsorption increases with increasing the adsorption time and reaches an equilibrium after about $120 \mathrm{~min}$ for both $\mathrm{MB}$ and $\mathrm{Cr}(\mathrm{III})$. The percentage of removal at which the adsorption reaches the equilibrium are roughly $90 \%$ and $60 \%$ for $\mathrm{MB}$ and $\mathrm{Cr}(\mathrm{III})$, respectively.

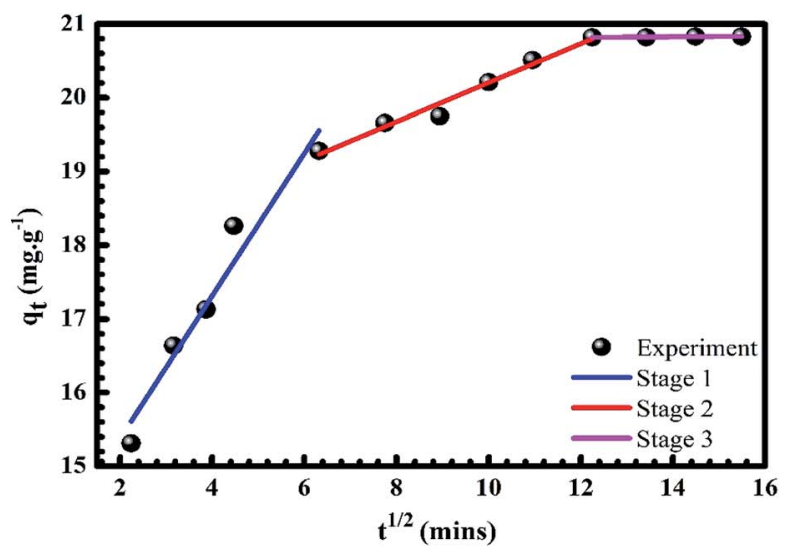

(a)

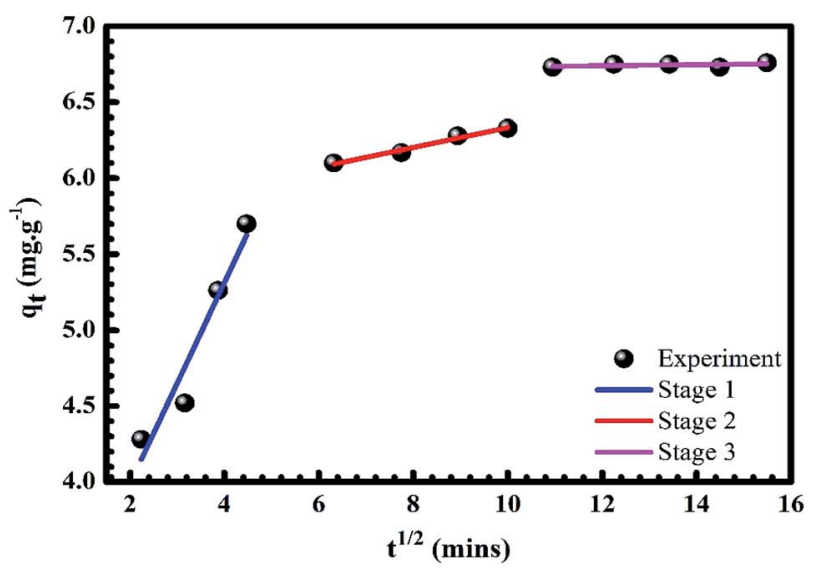

(b)

Fig. 11 Plots of intra-particle diffusion models of the adsorption of $\mathrm{Cr}(\mathrm{III})(\mathrm{a})$ and $\mathrm{MB}$ (b) onto pomelo fruit peel. 
Table 3 Kinetic parameters

\begin{tabular}{|c|c|c|c|}
\hline \multirow[b]{4}{*}{ Kinetics models } & \multicolumn{3}{|l|}{ Parameters } \\
\hline & \multirow[b]{2}{*}{$C_{\mathrm{o}}\left(\mathrm{mg} \mathrm{L}^{-1}\right)$} & \multirow{2}{*}{$\frac{\mathrm{MB}}{100}$} & \multirow{2}{*}{$\frac{\mathrm{Cr}(\mathrm{III})}{50}$} \\
\hline & & & \\
\hline & $q_{\text {e(exp) }}\left(\mathrm{mg} \mathrm{g}^{-1}\right)$ & 20.82 & 6.76 \\
\hline \multirow[t]{5}{*}{ Pseudo-first-order kinetic } & $q_{\mathrm{e}(\mathrm{cal})}\left(\mathrm{mg} \mathrm{g}^{-1}\right)$ & 19.90 & 6.44 \\
\hline & $k_{1}\left(\min ^{-1}\right)$ & 0.2323 & 0.1465 \\
\hline & RMSE & 1.137 & 0.4185 \\
\hline & $R^{2}$ & 0.6183 & 0.7605 \\
\hline & $\chi^{2}$ & 0.8768 & 0.4160 \\
\hline \multirow[t]{5}{*}{ Pseudo-second-order kinetic } & $\hat{q}_{\mathrm{e}(\mathrm{cal})}\left(\mathrm{mg} \mathrm{g}^{-1}\right)$ & 20.68 & 6.75 \\
\hline & $k_{2}\left(\mathrm{~g} \mathrm{mg}^{-1} \min ^{-1}\right)$ & 0.02210 & 0.0391 \\
\hline & RMSE & 0.4931 & 0.2140 \\
\hline & $R^{2}$ & 0.9282 & 0.9374 \\
\hline & $\chi^{2}$ & 0.1669 & 0.1100 \\
\hline \multirow[t]{5}{*}{ Elovich kinetic } & $\alpha$ & 16409 & 111.1 \\
\hline & $\beta$ & 0.6944 & 1.517 \\
\hline & RMSE & 0.3340 & 0.2112 \\
\hline & $R^{2}$ & 0.9671 & 0.9390 \\
\hline & $\chi^{2}$ & 0.07164 & 0.0974 \\
\hline \multirow[t]{5}{*}{ Intra-particle diffusion } & $\hat{K}_{\mathrm{P}}$ & 0.3765 & 0.1716 \\
\hline & $C$ & 15.95 & 4.531 \\
\hline & RMSE & 0.7313 & 0.3722 \\
\hline & $R^{2}$ & 0.8422 & 0.8105 \\
\hline & $\chi^{2}$ & 0.3589 & 0.3139 \\
\hline
\end{tabular}

3.1.4. Adsorbate initial concentration. In Fig. 6 and 7, we plot the influence of initial concentration on the adsorption of MB and Cr(III) onto pomelo fruit peel. Several noteworthy results are seen, namely the adsorption capacity increases with increasing the initial MB and $\mathrm{Cr}$ (III) concentrations at different temperatures. These results can be explained by the fact that the number of adsorption sites is higher (smaller) than that of the adsorbate molecules at low (high) concentrations, leading to the increase of the adsorption capacity. ${ }^{31}$ Notably, the numbers show a steady decrease in the MB adsorption capacity, which is inversely proportional to the increase of temperature from 303 $\mathrm{K}$ to $323 \mathrm{~K}$, whereas there is a reverse trend for the adsorption of Cr(III).

\subsection{Isotherm studies}

Plots of the nonlinear isotherm models for the biosorption of MB and Cr(III) onto pomelo fruit peels are shown in Fig. 8 and 9, whereas the calculated isotherm parameters are listed in Table 1. Based on the obtained RMSE and $\chi^{2}$ values given in Table 1, one can easily recognize that among four isothermal models, the Sips model gives the best fit to experimental data because it is a three-parameter model, which combines the Langmuir and Freundlich isotherms and works well in all the region of adsorbate concentrations. ${ }^{44}$ In addition, the $n$ values determined from the Freundlich model are in the range of 1 to 10 , confirming that the surface of this material is indeed heterogeneous. ${ }^{\mathbf{2 6 , 4 4 , 5 0}}$ Besides, the monolayer maximum adsorption capacities calculated from the Langmuir models at $303 \mathrm{~K}$ for
Table 4 Thermodynamic parameters

\begin{tabular}{|c|c|c|c|c|c|}
\hline Adsorbate & $T$ & $K_{\mathrm{C}}$ & $\begin{array}{l}\Delta G \\
\left(\mathrm{~kJ} \mathrm{~mol}^{-1}\right)\end{array}$ & $\begin{array}{l}\Delta H \\
\left(\mathrm{~kJ} \mathrm{~mol}^{-1}\right)\end{array}$ & $\Delta S\left(\mathrm{~J} \mathrm{~mol}^{-1}\right)$ \\
\hline \multirow[t]{3}{*}{ MB } & 303 & 11683 & -23.54 & -21.29 & 7.41 \\
\hline & 313 & 8330 & -23.61 & & \\
\hline & 323 & 6932 & -23.69 & & \\
\hline \multirow[t]{3}{*}{$\mathrm{Cr}(\mathrm{III})$} & 303 & 69998 & -28.08 & 4.98 & 109.13 \\
\hline & 313 & 72537 & -29.17 & & \\
\hline & 323 & 79168 & -30.27 & & \\
\hline
\end{tabular}

$\mathrm{Cr}(\mathrm{III})$ and $\mathrm{MB}$ are $11.29 \mathrm{mg} \mathrm{g}^{-1}$ and $218.5 \mathrm{mg} \mathrm{g}^{-1}$, respectively. By comparing with other studies shown in Table 2, it is obvious that although pomelo fruit peel is better at removing MB from aqueous solution than most of the biosorbents, it is not favourable for the removal of $\mathrm{Cr}$ (III) in the effluents.

Furthermore, the free energy values of the adsorption of MB and $\mathrm{Cr}$ (III) estimated from the Dubinin-Radushkevich are less than $8 \mathrm{~kJ} \mathrm{~mol}^{-1}$, demonstrating that the uptake of $\mathrm{MB}$ and $\mathrm{Cr}$ (III) onto pomelo fruit peel should follow the physical processes. $^{51}$

\subsection{Kinetic studies}

Fig. 10 and 11 show the plots of pseudo-first-order, pseudosecond-order, Elovich and intra-particle diffusion kinetic models, which are used to describe the adsorption rates of $\mathrm{Cr}$ (III) and $\mathrm{MB}$ onto pomelo fruit peels. The kinetic parameters of these models are listed in Table 3.

Equation of the pseudo-first-order equation is given $\mathrm{as}^{52}$

$$
q_{\mathrm{t}}=q_{\mathrm{e}}\left(1-\mathrm{e}^{-k_{1} t}\right)
$$

whereas that of the pseudo-second-order equation reads ${ }^{53}$

$$
q_{\mathrm{t}}=\frac{q_{\mathrm{e}}{ }^{2} k_{2} t}{1+k_{2} q_{\mathrm{e}} t} .
$$

Here $q_{\mathrm{e}}\left(\mathrm{mg} \mathrm{g}^{-1}\right)$ and $q_{\mathrm{t}}\left(\mathrm{mg} \mathrm{g}^{-1}\right)$ are, respectively, the amount of solute adsorbed per unit weight of adsorbent at equilibrium

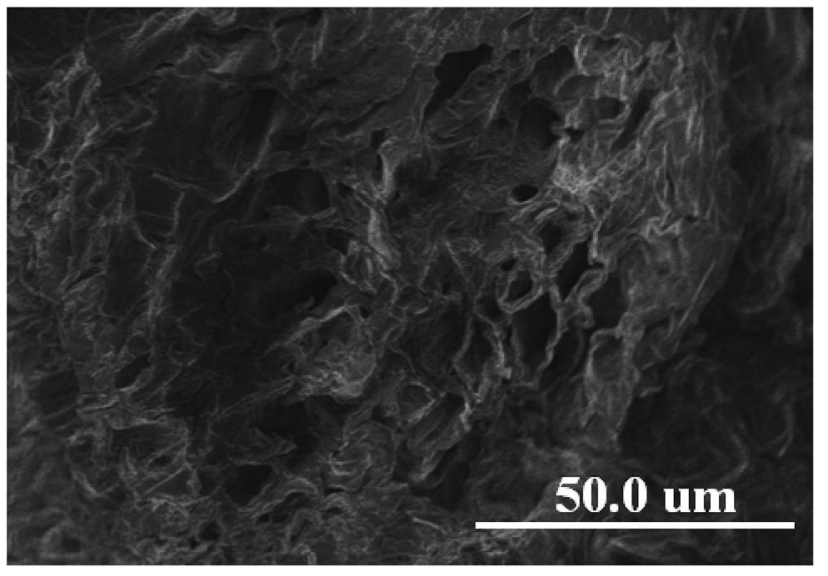

Fig. 12 SEM images of pomelo fruit peel. 

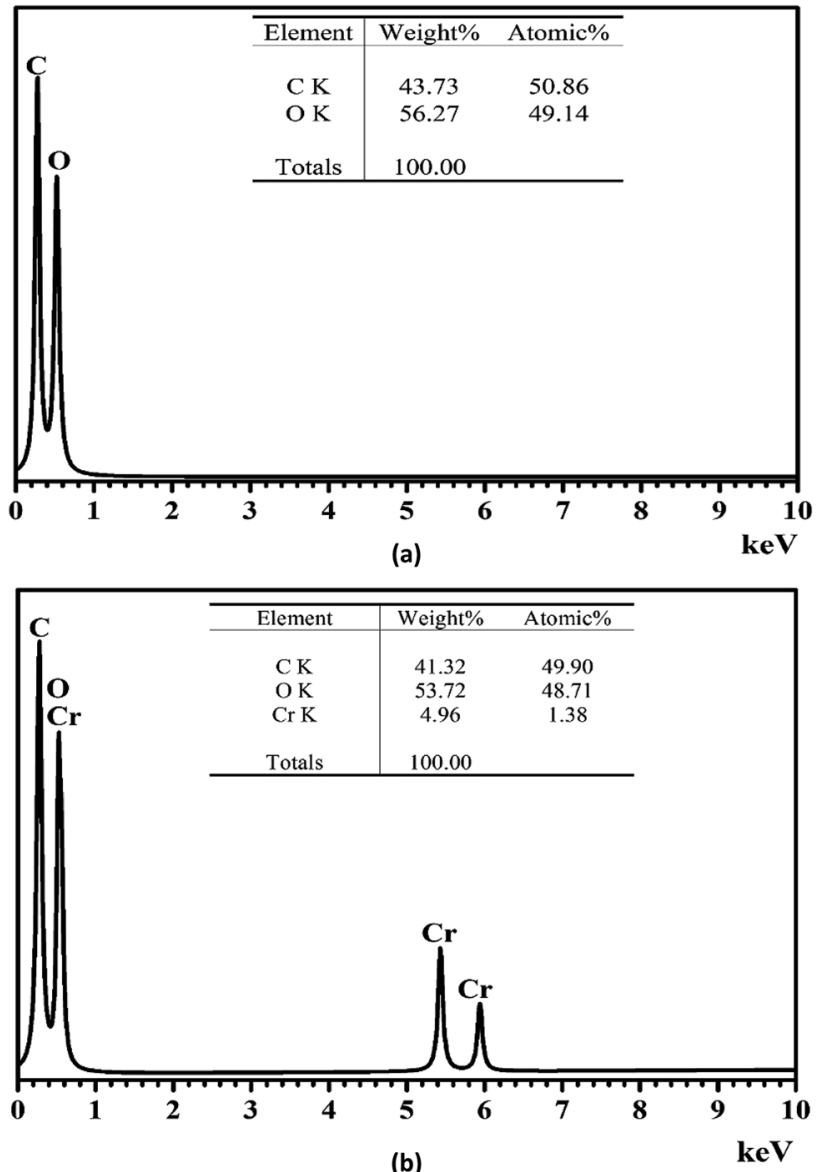

Fig. 13 EDX spectrum of pomelo fruit peel before (a) and after (b) the adsorption of $\mathrm{Cr}(\mathrm{III})$.

and the amount of solute adsorbed at any time, whereas $k_{1}$ and $k_{2}$ are the adsorption constants.

The Elovich model assumes that the adsorption sites increase exponentially with adsorption and this model is mainly applicable for the chemo-adsorption kinetics. It has the form $\mathrm{as}^{54}$

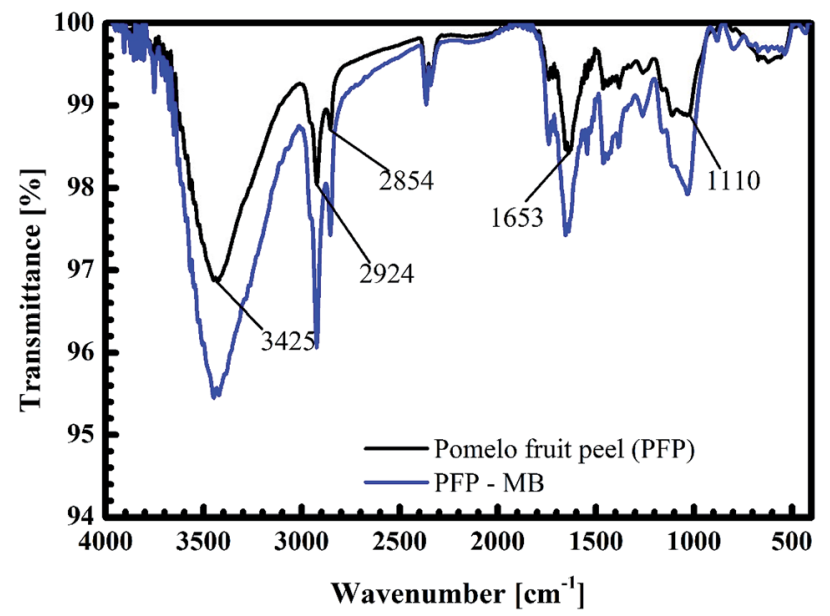

Fig. 14 FT-IR spectra of pomelo fruit peels before and after the adsorption MB.

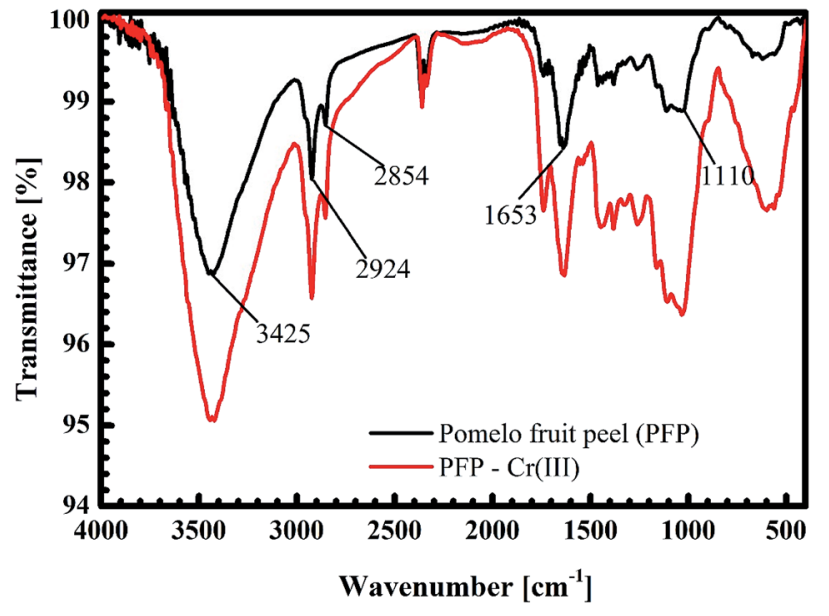

Fig. 15 FT-IR spectra of pomelo fruit peels before and after the adsorption $\mathrm{Cr}(\mathrm{III})$.

$$
q_{\mathrm{t}}=\frac{1}{\beta} \ln (1+\alpha \beta t)
$$

where $\beta\left(\mathrm{mg} \mathrm{g}^{-1}\right)$ and $\alpha\left(\mathrm{mg} \mathrm{g}^{-1} \mathrm{~min}^{-1}\right)$ are the desorption constant during any one experiment and the rate constants, respectively.

Results listed in Table 3 indicate that among the three models above, the Elovich model gives the best agreement with the experimental data at different initial concentration as it produces the highest $R^{2}$ and lowest $\chi^{2}$ values. Moreover, one can also see from Table 3 that the pseudo-second-order equation is in a better agreement with the experimental data than the pseudo-first-order one and the $q_{\text {e(cal) }}$ values obtained within this model are very close to the experimental data for both MB and $\mathrm{Cr}(\mathrm{III})$.

However, the diffusion mechanisms cannot be identified via the pseudo-first-order and pseudo-second-order models; hence, Weber and Morris ${ }^{55}$ have developed the intraparticle-diffusion model, whose equation is given as

$$
q_{\mathrm{t}}=k_{\mathrm{d}} t^{1 / 2}+C
$$

where $C$ characterises the effects caused by the boundary layer and $k_{\mathrm{d}}$ is the diffusion constant. The results of the present study demonstrate that the uptakes of $\operatorname{Cr}(\mathrm{III})$ and $\mathrm{MB}$ onto the pomelo fruit peel surface are likely to occur via three stages. In the first stage [blue lines in Fig. 11a and b], there is a bulk diffusion process within about $40 \mathrm{~min}$ at which $\mathrm{Cr}(\mathrm{III})$ and $\mathrm{MB}$ have a quick transfer from the solution to the boundary film of the particles. Next, there is a gradual adsorption occurring during the time interval from 40 to $120 \mathrm{~min}$ in the second stage (red lines in Fig. 11a and b). This stage is known as the sole rate-determining step. Moreover, one can also easily see that within this second stage the $q_{\mathrm{t}}$ plot does not cross the origin and the presence of the boundary layer effect is characterised by the nonzero value of $C$. These results indicate that the adsorption follows not only the intraparticle diffusion but also two or more different mechanisms of the diffusion. ${ }^{56}$ In the last stage (violet lines in Fig. 11a and b), the equilibrium is reached because of two factors, 


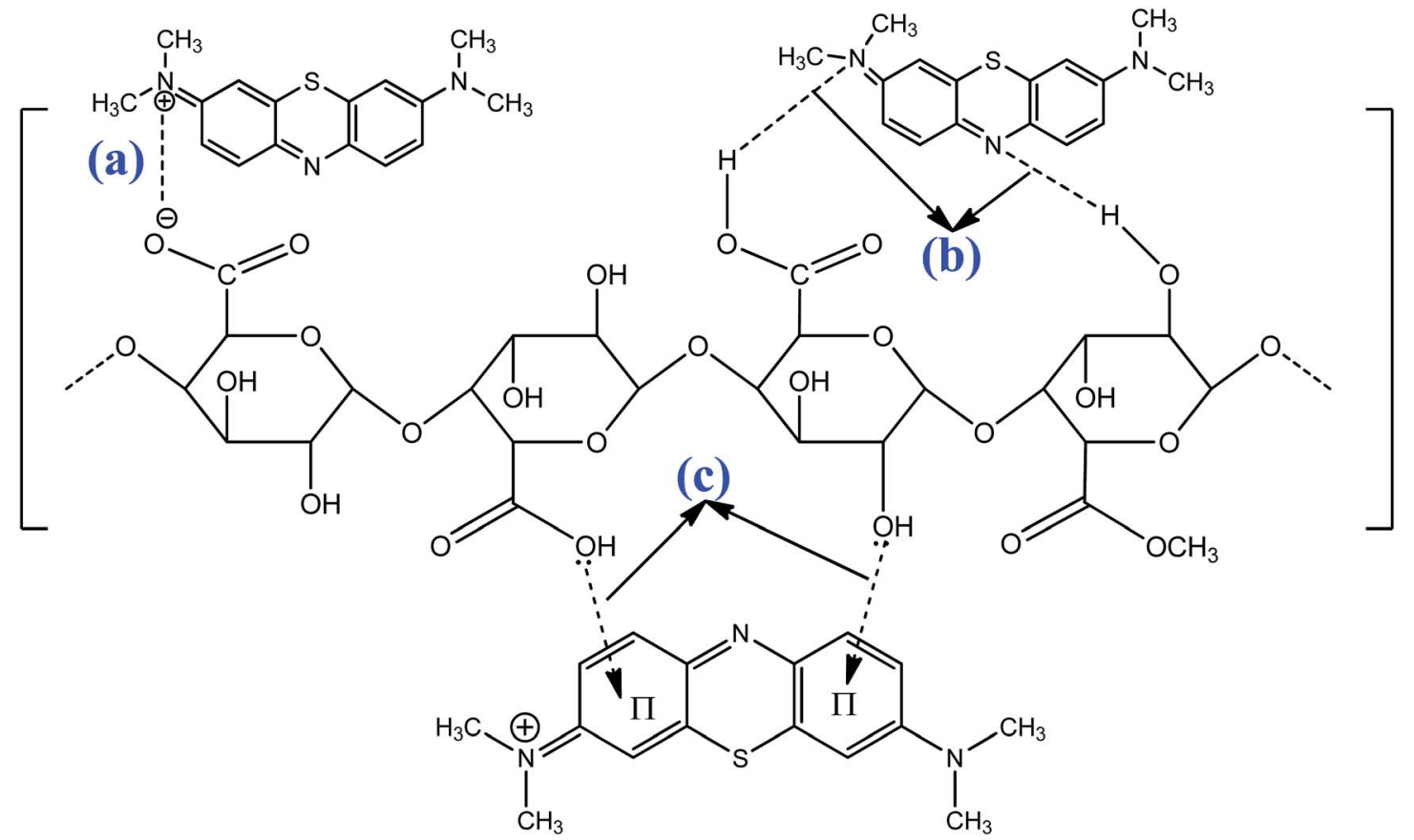

Fig. 16 Possible adsorption mechanisms of $\mathrm{MB}(\mathrm{pH}=10>\mathrm{pH}$ PzC): electrostatic attraction (a), hydrogen bonding (b), and $\mathrm{n}-\pi$ interactions (c).

namely the extremely low concentration of $\mathrm{Cr}(\mathrm{III})$ and $\mathrm{MB}$ in the solution and the decrease in the number of adsorption sites. ${ }^{26,57}$

\subsection{Thermodynamics}

The thermodynamic parameters such as the Gibbs free energy $(\Delta G)$ and the enthalpy $(\Delta H)$ and entropy $(\Delta S)$ differences are computed by using the $\mathrm{MB}$ or $\mathrm{Cr}(\mathrm{III})$ adsorption data at temperatures of $303 \mathrm{~K}, 313 \mathrm{~K}$, and $323 \mathrm{~K}$. These parameters follow the Gibbs isotherm as ${ }^{58}$

$$
\Delta G=\Delta H-T \Delta S .
$$

The quantity $\Delta G$, which is a function of temperature, can be calculated from the following van't Hoff equation ${ }^{59}$

$$
\Delta G=-R T \ln K_{\mathrm{C}}
$$

where $T(\mathrm{~K})$ is the absolute temperature and $K_{\mathrm{C}}\left(\mathrm{L} \mathrm{mol}^{-1}\right)$ is the equilibrium constant. Meanwhile, the values of $\Delta H$ and $\Delta S$ can be determined from the intercept and slope of the plots of $\ln \left(K_{\mathrm{c}}\right)$ versus $1 / T$, that is ${ }^{49}$

$$
\ln K_{\mathrm{C}}=\frac{\Delta S}{R}-\frac{\Delta H}{R T}
$$

Table 4 presents the values of thermodynamic parameters obtained within the present study for MB and $\mathrm{Cr}$ (III). It should be noted that the negative values of $\Delta G$ indicate a spontaneous process taking place between $\mathrm{MB}$ or $\mathrm{Cr}(\mathrm{III})$ and pomelo fruit peel, that is, the increase in the negative value of the Gibbs free energy with temperature is associated with a much more stable and energetically favourable adsorption of $\mathrm{MB}$ and $\mathrm{Cr}(\mathrm{III})$ at high temperatures. In addition, the values of the adsorption heat $\Delta H$



Fig. 17 Possible adsorption mechanisms of $\mathrm{Cr}(\mathrm{III})\left(\mathrm{pH}=5>\mathrm{pH}_{\mathrm{PZC}}\right)$ : electrostatic attraction (a), and $\mathrm{n}-\mathrm{d}$ interactions (b). 

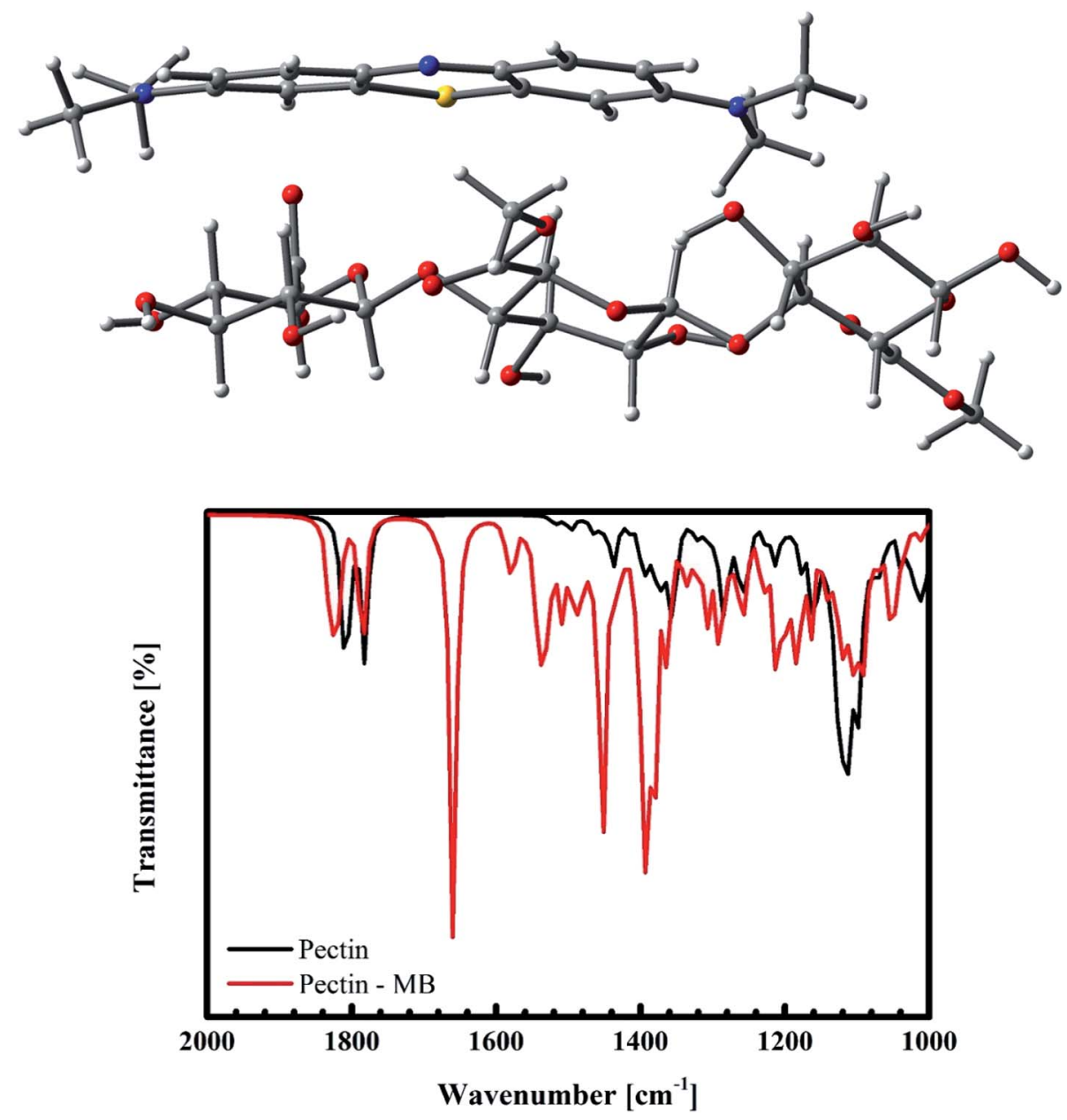

Fig. $18 A b$ initio simulation of the interaction between MB and pomelo fruit peel.

obtained within the present study are $-21.29 \mathrm{~kJ} \mathrm{~mol}^{-1}$ and $4.98 \mathrm{~kJ} \mathrm{~mol}^{-1}$ for $\mathrm{MB}$ and $\mathrm{Cr}(\mathrm{III})$, respectively, which are both less than $40 \mathrm{~kJ} \mathrm{~mol}^{-1}$. We are therefore able to conclude that the adsorptions of $\mathrm{MB}$ or $\mathrm{Cr}(\mathrm{III})$ onto pomelo fruit peel are essentially following the physical adsorption processes.

\subsection{SEM-EDX analysis}

The morphology of pomelo fruit peel is investigated by using the ultra high-resolution scanning electron microscopy (SEM). The SEM image presented in Fig. 12 suggests that this adsorbent has a rugged surface and some cavities in its structure that are favourable for the uptake of MB and heavy metal ions. In addition, the elemental composition of pomelo fruit peel before the uptake of $\mathrm{Cr}(\mathrm{III})$ and $\mathrm{MB}$ is examined by using the energy-dispersive X-ray spectroscopy (EDX) and the results are depicted in Fig. 13a. The figure reveals that the main composition of the material includes $\mathrm{C}$ and $\mathrm{O}$ with $43.73 \mathrm{wt} \%$ and $56.27 \mathrm{wt} \%$, respectively. Moreover, the appearance of the main characteristic peaks of $\mathrm{Cr}$ at $0.573,5.415$ and $5.947 \mathrm{keV}$ in the EDX spectrum of pomelo fruit peel after the $\mathrm{Cr}$ (III) adsorption (Fig. 13b) indicates that $\mathrm{Cr}$ (III) ions have been successfully absorbed by pomelo fruit peel. Similar studies have also been reported. ${ }^{26,60}$

\subsection{FT-IR analysis}

The black curves in Fig. 14 and 15 present the FT-IR spectrum of pomelo fruit peel. This spectrum exhibits a specific band at $3425 \mathrm{~cm}^{-1}$, which is related to the stretching vibration of $-\mathrm{O}-\mathrm{H}$ groups (alcohols, phenols, and carboxylic acids) as in pectin, cellulose and lignin on the surface of the biosorbent. ${ }^{61}$ The spectrum peaks at around 2924 and $2855 \mathrm{~cm}^{-1}$ can be assigned to the stretching vibrations of $\mathrm{C}-\mathrm{H}$, whereas the peak observed at $1653 \mathrm{~cm}^{-1}$ can be attributed to the stretching vibration of $\mathrm{C}=\mathrm{O}$ bond. ${ }^{61,62}$ The band at $1110 \mathrm{~cm}^{-1}$ confirms the stretching vibration of $\mathrm{C}-\mathrm{O}$ in the lignin structure of grapefruit peel. ${ }^{63}$ Furthermore, the FT-IR spectra of pomelo fruit peel after the adsorption of MB and $\mathrm{Cr}(\mathrm{III})$ are plotted in Fig. 14 (black curve) and Fig. 15 (read curve). In Fig. 14, in comparison with the results obtained for pomelo fruit peel, that is, without $\mathrm{MB}$, the intensity of all the specific peaks of pomelo fruit peel, which characterise the $-\mathrm{O}-\mathrm{H}$ groups, $\mathrm{C}=\mathrm{O}$ and $-\mathrm{C}-\mathrm{O}$ bonds, is increased. These results indicate that the adsorption of $\mathrm{MB}$ onto pomelo fruit peel occurs via the above-named functional groups. Similarly, the change in the intensity of these specific peaks after the adsorption of $\mathrm{Cr}(\mathrm{III})$, depicted by the red curve in 

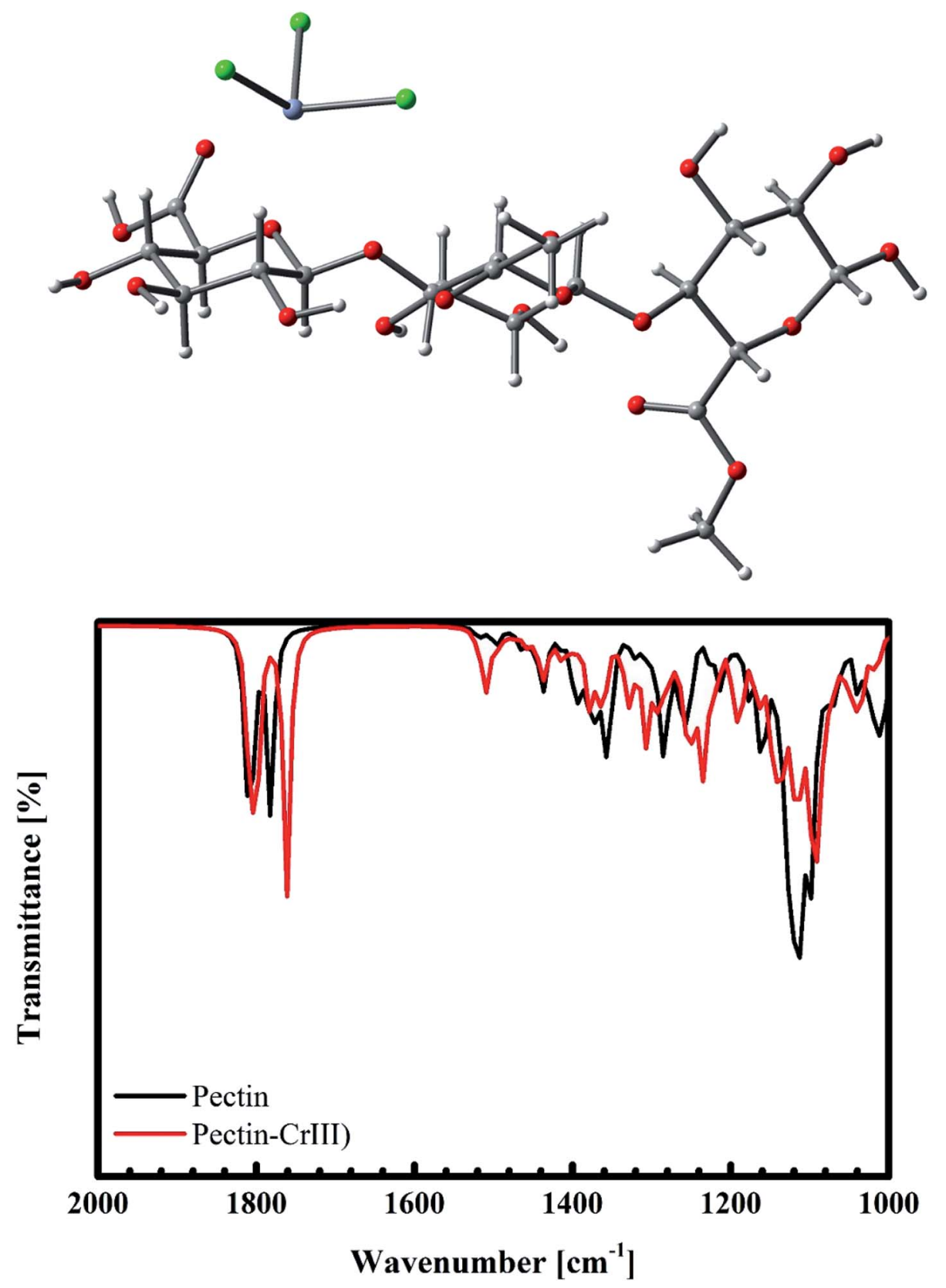

Fig. 19 Ab initio simulation of the interaction between $\mathrm{Cr}(\mathrm{II})$ and pomelo fruit peel.

Fig. 15, demonstrates the interaction between $\mathrm{Cr}(\mathrm{III})$ and pomelo fruit peel surface.

\subsection{Proposal of the possible adsorption mechanisms}

The possible mechanisms of cationic MB adsorption onto pomelo fruit peel are as follows: (1) electrostatic attraction, (2) hydrogen bonding and (3) $n-\pi$ interactions; ${ }^{49}$ whereas those of $\mathrm{Cr}$ (III) uptake onto this material are: (1) electrostatic attraction and (2) $n-\pi$ interactions.

The electrostatic attraction mechanisms can be explained based on the interaction between cationic MB and $\mathrm{Cr}$ (III) and negatively charged sites on the surface of pomelo fruit peel when $\mathrm{pH}_{\text {solution }}>\mathrm{pH}_{\mathrm{PZC}}$. Obviously, the $\mathrm{pH}$ values of solution used in the present work, which are approximately 5.0 for $\mathrm{Cr}$ (III) and roughly 10 for $\mathrm{MB}$, are higher than the $\mathrm{pH}_{\mathrm{PZC}}$ values, thus, the carboxylic groups are deprotonated and negatively charged carboxylate ligands $\left(-\mathrm{COO}^{-}\right)$binding the charged $\mathrm{MB}$ and $\mathrm{Cr}$ (III) molecules as shown in Fig. 16a and 17a. These results are related to the studies of Tran et al. ${ }^{49}$ and Salazar-Rabago et al. ${ }^{3}$

In addition, the hydrogen bonding interactions, which can be formed between the surface hydrogens of the hydroxyl groups $(\mathrm{H}$ donors) on the pomelo fruit peel's surface and the nitrogen atoms (H-acceptors) of MB. This phenomenon is also known as the dipole-dipole hydrogen bonding (Fig. 16b). It can be seen from the FT-IR spectrum of the MB adsorbed sample (blue curve in Fig. 14) that the intensity of the $-\mathrm{OH}$ groups at around $3400 \mathrm{~cm}^{-1}$ 
dramatically decreases and shifts toward the minimally higher wavenumbers, confirming the existence of the dipole-dipole bonding interaction. ${ }^{49}$ The $n-\pi$ or $n-d$ interactions are formed between the electron donor atoms including pairs of electrons, such as oxygen or nitrogen, and acceptors that are aromatic rings or free d orbitals in metal ions. In this study, oxygen in the carbonyl groups on the surface of the adsorbent acts as an electron donor and the aromatic rings of $\mathrm{MB}$ and free $\mathrm{d}$ orbitals of $\mathrm{Cr}(\mathrm{III})$ act as electron acceptors (Fig. 16c and 17b).

In order to understand deeply which interactions are dominant in the present experiment, a computer simulation within the $a b$ initio calculations has been carried out. Within the optimization, the interactions between $\mathrm{MB}$ and pectin, the primary recipe of pomelo fruit peel, are calculated using the Gaussian suite of program ${ }^{64}$ with the B3LYP functional ${ }^{65}$ and the 6-31g* and LANL2dz (for Cr) basis sets. ${ }^{66-68}$ After structural optimisations, the obtained vibrational infrared results indicate that MB mainly interacts with pectin through the weak electrostatic forces and hydrogen bonding. This results in a slight shift of the vibrational modes and their corresponding change in the IR intensity (Fig. 18b). Moreover, it can be confirmed through the quantum mechanical calculations that there exist no $\mathrm{n}-\pi$ interactions between MB and pectin. Such modelling results are in good accordance with the FT-IR spectra of this material after the adsorption of MB shown in Fig. 14. We should be therefore able to state again that the interacting mechanism here is mainly constituted by the electrostatic force and weak hydrogen bonding.

For the case of $\mathrm{Cr}(\mathrm{III})$ interacting with pectin, besides the weak electrostatic interaction, $\mathrm{Cr}(\mathrm{III})$ tends to exhibit a bonding distance of $2.097 \AA$ to oxygen on the $-\mathrm{C}=\mathrm{O}$ group. This results in a shift of $20 \mathrm{~cm}^{-1}$ for the $-\mathrm{C}=\mathrm{O}$ vibration from $1781 \mathrm{~cm}^{-1}$ (Fig. 19b), as confirmed by our previous experimental data (from $1655 \mathrm{~cm}^{-1}$ to $1633 \mathrm{~cm}^{-1}$, as shown in Fig. 15). Therefore, we predict that the adsorption of $\mathrm{Cr}(\mathrm{III})$ is produced as a result of both electrostatics and $\mathrm{n}-\mathrm{d}$ mechanism.

\section{Conclusions}

In the present study, the phenomenon and biosorption mechanisms of $\mathrm{MB}$ and $\mathrm{Cr}(\mathrm{III})$ onto pomelo fruit peel are investigated. It has been found that $\mathrm{pH}$ plays an important role in removing $\mathrm{MB}$ and $\mathrm{Cr}(\mathrm{III})$ from aqueous solution. Moreover, based on the kinetic studies, we have demonstrated that the adsorption of $\mathrm{MB}$ and $\operatorname{Cr}(\mathrm{III})$ onto pomelo fruit peel has occurred in three distinguished stages, namely the bulk diffusion process, the gradual adsorption and the adsorption equilibrium. By combining the experimental data with the ab inito calculations, we have indicated, for the first time, that the uptake of MB can be occurred due to two adsorption mechanisms: electrostatic attraction and hydrogen bonding, whereas the biosorption of $\mathrm{Cr}(\mathrm{III})$ can be happened via the electrostatic attraction and n$\mathrm{d}$ interaction mechanisms. This is the most important result of the present study. Finally, the maximum monolayer adsorption capacity of MB is found to be $218.5 \mathrm{mg} \mathrm{g}^{-1}$ at $303 \mathrm{~K}$, which is higher than other popular biosorbents. This result demonstrates that pomelo fruit peel shall be a low-cost, environmentally friendly material for the removal of $\mathrm{MB}$ from effluents.

\section{Conflicts of interest}

There are no conflicts to declare.

\section{References}

1 V. Geissen, H. Mol, E. Klumpp, G. Umlauf, M. Nadal, M. van der Ploeg, S. E. A. T. M. van de Zee and C. J. Ritsema, International Soil and Water Conservation Research, 2015, 3, 57-65.

2 V. Vadivelan and K. V. Kumar, J. Colloid Interface Sci., 2005, 286, 90-100.

3 J. J. Salazar-Rabago, R. Leyva-Ramos, J. Rivera-Utrilla, R. Ocampo-Perez and F. J. Cerino-Cordova, Sustainable Environ. Res., 2017, 27, 32-40.

4 D. Pathania, S. Sharma and P. Singh, Arabian J. Chem., 2017, 10, S1445-S1451.

5 K. V. Kumar, V. Ramamurthi and S. Sivanesan, J. Colloid Interface Sci., 2005, 284, 14-21.

6 W.-S. Zhong, T. Ren and L.-J. Zhao, J. Food Drug Anal., 2016, 24, 46-55.

7 A.-L. Alanne, M. Tuikka, K. Tõnsuaadu, M. Ylisirniö, L. Hämäläinen, P. Turhanen, J. Vepsäläinen and S. Peräniemi, RSC Adv., 2013, 3, 14132-14138.

8 J. H. Luo, J. Li, Y. B. Qi and Y. Q. Cao, Desalin. Water Treat., 2013, 51, 2130-2134.

9 D. Mohan, K. P. Singh and V. K. Singh, J. Hazard. Mater., 2006, 135, 280-295.

10 S. O. Owalude and A. C. Tella, Beni-Seuf Univ. J. Appl. Sci., 2016, 5, 377-388.

11 A. Ali, K. Saeed and F. Mabood, Alexandria Eng. J., 2016, 55, 2933-2942.

12 M. A. Khan, Z. A. Alothman, M. Naushad, M. R. Khan and M. Luqman, Desalin. Water Treat., 2015, 53, 515-523.

13 E. Altintig, H. Altundag, M. Tuzen and A. Sarı, Chem. Eng. Res. Des., 2017, 122, 151-163.

14 G. Qin, M. J. McGuire, N. K. Blute, C. Seidel and L. Fong, Environ. Sci. Technol., 2005, 39, 6321-6327.

15 A. Esmaeili, E. Hejazi and A. H. Hassani, Water, Air, Soil Pollut., 2014, 225, 2140.

16 N. W. Zainon Najib, F. M. Ridwan, A. M. Syakirah and B. S. Lim, Study of Methylene Blue color removal effectiveness by moringa oleifera and alum, 2012.

17 S. K. Mondal and P. Saha, Chem. Eng. Res. Des., 2018, 132, 564-583.

18 J. Wang, Z. Wu, T. Li, J. Ye, L. Shen, Z. She and F. Liu, Chem. Eng. J., 2018, 334, 579-586.

19 S. Rengaraj, K.-H. Yeon and S.-H. Moon, J. Hazard. Mater., 2001, 87, 273-287.

20 L. Rafati, A. H. Mahvi, A. R. Asgari and S. S. Hosseini, Int. J. Environ. Sci. Technol., 2010, 7, 147-156.

21 R. Giovanardi and G. Orlando, Surf. Coat. Technol., 2011, 205, 3947-3955.

22 A. Çimen, Russ. J. Phys. Chem. A, 2015, 89, 1238-1243. 
23 V.-P. Dinh, N.-C. Le, T.-P.-T. Nguyen and N.-T. Nguyen, J. Chem., 2016, 2016, 9.

24 V.-P. Dinh, N.-C. Le, V.-D. Nguyen and N.-T. Nguyen, Desalin. Water Treat., 2017, 58, 427-434.

25 V.-P. Dinh, N.-C. Le, T.-D. Le, T.-A. Bui and N.-T. Nguyen, J. Electron. Mater., 2017, 46, 3681-3688.

26 V.-P. Dinh, N.-C. Le, L. A. Tuyen, N. Q. Hung, V.-D. Nguyen and N.-T. Nguyen, Mater. Chem. Phys., 2018, 207, 294-302.

27 M. E. Argun, S. Dursun, C. Ozdemir and M. Karatas, J. Hazard. Mater., 2007, 141, 77-85.

28 L. Chen, A. Ramadan, L. Lü, W. Shao, F. Luo and J. Chen, J. Chem. Eng. Data, 2011, 56, 3392-3399.

29 R. Maurya, T. Ghosh, C. Paliwal, A. Shrivastav, K. Chokshi, I. Pancha, A. Ghosh and S. Mishra, PLoS One, 2014, 9, e109545.

30 R. Saha and B. Saha, Desalin. Water Treat., 2014, 52, 19281936.

31 M. Mahmood-ul-Hassan, V. Suthor, E. Rafique and Y. Muhammad, Environ. Monit. Assess., 2015, 187, 8.

32 E. Rosales, J. Meijide, T. Tavares, M. Pazos and M. Sanromán, Process Saf. Environ. Prot., 2016, 101.

33 J. Liu, G. Huang, J. Deng, K. Liu and Y. Xie, J. Ecol. Rural Environ., 2012, 28, 187-191.

34 M. K. Dahri, M. R. R. Kooh and L. B. L. Lim, J. Environ. Biotechnol. Res., 2017, 6, 238-247.

35 M. E. Argun, D. Güclü and M. Karatas, J. Ind. Eng. Chem., 2014, 20, 1079-1084.

36 H. Li, Z. Sun, L. Zhang, Y. Tian, G. Cui and S. Yan, Colloids Surf., A, 2016, 489, 191-199.

37 P. Tasaso, J. Clean Energy Technol., 2014, 2, 154-157.

38 Y. Wu, L. Cha, Y. Fan, P. Fang, Z. Ming and H. Sha, Water, Air, Soil Pollut., 2017, 228, 405.

39 S. X. Hou, in Advanced Materials Research, Trans Tech Publ, 2013, pp. 178-181.

40 M. Thomas, M. Brehm, R. Fligg, P. Vöhringer and B. Kirchner, Phys. Chem. Chem. Phys., 2013, 15, 6608-6622.

41 M. Gastegger, J. Behler and P. Marquetand, Chem. Sci., 2017, 8, 6924-6935.

42 X. Yu, L. Huang, Y. Wei, J. Zhang, Z. Zhao, W. Dai and B. Yao, Mater. Res. Bull., 2015, 64, 410-417.

43 A. M. Cardenas-Peña, J. G. Ibanez and R. Vasquez-Medrano, Int. J. Electrochem. Sci., 2012, 7, 6142-6153.

44 K. Y. Foo and B. H. Hameed, Chem. Eng. J., 2010, 156, 2-10. 45 I. Langmuir, J. Am. Chem. Soc., 1918, 40, 1361-1403.

46 H. M. F. Freundlich, J. Phys. Chem., 1906, 57, 385-471.

47 M. J. Temkin and V. Pyzhev, Acta Physicochim. URSS, 1940, 12, 217-225.

48 R. R. Bhatt and B. A. Shah, Arabian J. Chem., 2015, 8, 414426.

49 H. Tran, S.-J. You, T. V. Nguyen and H.-P. Chao, Chem. Eng. Commun., 2017, 204, 1020-1036.

50 M. Rafatullah, O. Sulaiman, R. Hashim and A. Ahmad, J. Hazard. Mater., 2009, 170, 969-977.

51 J. Anwar, U. Shafique, Z. Waheed uz, M. Salman, A. Dar and S. Anwar, Bioresour. Technol., 2010, 101, 1752-1755.

52 R.-L. Tseng, F.-C. Wu and R.-S. Juang, J. Taiwan Inst. Chem. Eng., 2010, 41, 661-669.

53 Y. S. Ho and G. McKay, Process Biochem., 1999, 34, 451-465.
54 A. M. Aljeboree, A. N. Alshirifi and A. F. Alkaim, Arabian J. Chem., 2017, 10, S3381-S3393.

55 W. J. Weber and J. C. Morris, J. Sanit. Eng. Div., Am. Soc. Civ. Eng., 1963, 89, 31-60.

56 S. Vasiliu, I. Bunia, S. Racovita and V. Neagu, Carbohydr. Polym., 2011, 85, 376-387.

57 F.-C. Wu, R.-L. Tseng and R.-S. Juang, J. Hazard. Mater., 2000, $73,63-75$.

58 V. J. Inglezakis and A. A. Zorpas, Desalin. Water Treat., 2012, 39, 149-157.

59 A. B. Albadarin, C. Mangwandi, A. a. H. Al-Muhtaseb, G. M. Walker, S. J. Allen and M. N. M. Ahmad, Chem. Eng. J., 2012, 179, 193-202.

60 T. A. Saleh, A. Sarı and M. Tuzen, J. Environ. Chem. Eng., 2017, 5, 1079-1088.

61 M. Torab-Mostaedi, M. Asadollahzadeh, A. Hemmati and A. Khosravi, J. Taiwan Inst. Chem. Eng., 2013, 44, 295-302.

62 G. Zhang, Y. Sun, Y. Guo, J. Liu, L. Wu and J. Lin, J. Sci. Food Agric., 2018, 98, 4135-4141.

63 N. V. Farinella, G. D. Matos and M. A. Z. Arruda, Bioresour. Technol., 2007, 98, 1940-1946.

64 M. J. Frisch, G. W. Trucks, H. B. Schlegel, G. E. Scuseria, M. A. Robb, J. R. Cheeseman, G. Scalmani, V. Barone, B. Mennucci, G. A. Petersson, H. Nakatsuji, M. Caricato, X. Li, H. P. Hratchian, A. F. Izmaylov, J. Bloino, G. Zheng, J. L. Sonnenberg, M. Hada, M. Ehara, K. Toyota, R. Fukuda, J. Hasegawa, M. Ishida, T. Nakajima, Y. Honda, O. Kitao, H. Nakai, T. Vreven, J. A. Montgomery, J. E. Peralta, F. Ogliaro, M. Bearpark, J. J. Heyd, E. Brothers, K. N. Kudin, V. N. Staroverov, R. Kobayashi, J. Normand, K. Raghavachari, A. Rendell, J. C. Burant, S. S. Iyengar, J. Tomasi, M. Cossi, N. Rega, J. M. Millam, M. Klene, J. E. Knox, J. B. Cross, V. Bakken, C. Adamo, J. Jaramillo, R. Gomperts, R. E. Stratmann, O. Yazyev, A. J. Austin, R. Cammi, C. Pomelli, J. W. Ochterski, R. L. Martin, K. Morokuma, V. G. Zakrzewski, G. A. Voth, P. Salvador, J. J. Dannenberg, S. Dapprich, A. D. Daniels, Ö Farkas, J. B. Foresman, J. V. Ortiz, J. Cioslowski and D. J. Fox, Gaussian 09, Revision D.01, Wallingford CT, USA, 2009.

65 A. D. Becke, J. Chem. Phys., 1993, 98, 5648-5652.

66 V. A. Rassolov, J. A. Pople, M. A. Ratner and T. L. Windus, J. Chem. Phys., 1998, 109, 1223-1229.

67 V. A. Rassolov, M. A. Ratner, J. A. Pople, P. C. Redfern and L. A. Curtiss, J. Comput. Chem., 2001, 22, 976-984.

68 P. J. Hay and W. R. Wadt, J. Chem. Phys., 1985, 82, 270-283. 69 G. Annadurai, R.-S. Juang and D.-J. Lee, J. Hazard. Mater., 2002, 92, 263-274.

70 N. Priyantha, L. B. L. Lim, D. T. B. Tennakoon, E. T. Z. Liaw, C. H. Ing and A. B. Liyandeniya, Appl. Water Sci., 2018, 8, 37. 71 L. B. L. Lim, N. Priyantha, C. Hei Ing, M. Khairud Dahri, D. T. B. Tennakoon, T. Zehra and M. Suklueng, Desalin. Water Treat., 2015, 53, 964-975.

72 N. Priyantha, L. Lim and M. Dahri, Int. Food Res. J., 2015, 22, 2141-2148.

73 L. B. L. Lim, N. Priyantha, D. T. B. Tennakoon, H. I. Chieng, M. K. Dahri and M. Suklueng, Arabian J. Chem., 2017, 10, S3216-S3228. 